\title{
ALTERNATIVE MODELS TO EXTRACT ASSET VOLATILITY: A COMPARATIVE STUDY*
}

\author{
Pedro L. Valls Pereira**
}

Luiz K. Hotta $* *$

Luiz Alvares R. de Souza***

Nuno Miguel C. G. de Almeida****

\section{Abstract}

This paper presents an empirical comparison of the estimation of the volatility of three Brazilian financial series: a Brazilian Brady bond (the Cbond), a stock (Telebrás PN) and the Brazilian Real/US Dollar exchange rate, using different modelling methods. The models used are: XARCH family, Stochastic Volatility (SV) and the switching in the variance model (SWARCH). The comparison is done using three criteria: loss functions, which compare the square of the estimated volatility with the instantaneous volatility, a procedure proposed by Herencia et alii (1998) which used prediction confidence intervals and one-stepahead prediction, and a prediction exercise for the last 100 observations. In general the SV model presented the best performance although it is dominated by other models in some criteria.

\section{Resumo}

Este artigo compara métodos de estimaçâo de volatilidade para diversos ativos, a saber, a taxa de câmbio real por dólar, título da dívida brasileira Cbond

\footnotetext{
* This work was first presented as an inviated paper in the Special Section in Volatility at the XX Brazilian Econometric Meeting. The authors would like to thank Ajax Moreira for the invitation and the participants of that section for all the comments. This paper was also presented in seminars at Nuffield College, LSE and Carlos III. The authors also thank Miguel Delgado, Jurgen Dooenik, Toni Espasa, David Hendry, Jeremy Penger and Daniel leña for helpful comments. All authors acknowedge the financial support from CNPq and the first two also from PRONEX.

** Department of Statistics USP and IBMEC Business School.

*** Department of Statistics UNICAMP.

**** Department of Economics USP.
}

\begin{tabular}{llll}
\hline R. de Econometria & Rio de Janeiro & v. $19, \mathrm{n}^{\mathrm{Q}} 1$, pp. $57-109$ & Maio 1999 \\
\hline
\end{tabular} 
e a série de Telebrás PN. Os métodos de estimaçâo sâo: os da familia XAR.CH, Volatilidade Estocástica (VE) e de Mudança Markoviana de Regime na Variância (SWARCH). As comparações, para todas as séries, sâo feitas usando-se três critérios: funções de perda que comparam o quadrado da volatilidade estimada com a variância instantânea, o procedimentoproposto por Herencia et alii (1998) que utiliza intervalos de previsâo a um passo a frente, e um exercício preditivo para as últimas 100 observações. Podemos afirmar que o Modelo de Volatilidade Estocástica é aquele que apresenta melhor desempenho, embora seja dominado em alguns dos critérios pelos outros modelos.

Key Words: Volatility; GARCH; stochastic volatility; SWARCH; prediction.

JEL Code: C22, C52 and G10.

\section{Introduction}

We can find several papers in the literature which compare empirically volatility models for the returns. For instance, Pagan \& Schwert (1990) compare ARCH models with an alternative non parametric models; Cao \& Tsay (1993) compare TAR and ARCH models and Taylor (1994) compares ARCH and Stochastic Volatility (SV) models. We can also find theoretical studies like the papers of Nelson \& Foster (1994) and Foster \& Nelson (1996) which compare ARCH and Stochastic Volatility in continuous time and the Jacquier et alii (1994) paper which compare estimates of the AR(1)-SV model using quasi-maximum likelihood (QML) and Markov Chain Monte Carlo (MCMC) approaches. The major problem in the comparison comes from the fact that, in practice, the volatility is not observed. In order to overcome this problem a solution often used is to use as a benchmark for the monthly volatility the monthly unconditional standard deviation of the daily returns. An alternative suggested by Hamilton \& Susmel (1994) is to use some loss functions which compare the square of the estimated volatility with the instantaneous volatility. Another alternative is to use the unconditional sample standard deviation using a rolling window of 20 or 40 days. This practice was 
very popular in the financial market although presents some problems. A different approach suggested by Herencia et alii (1998) is to compare the point estimate and the one-step-ahead prediction of the volatility with the instantaneous volatility. A comparison of the point estimates is basically qualitative whereas in the comparison of the one-step-ahead prediction it is used a criterion based on the observed returns as described previously in more detail in Herencia et alii (1995).

The empirical comparison of the ARCH, SV and SWARCH model is done using three Brazilian financial series: a stock (Telebrás PN), a Brazilian Brady bond (the Cbond) and Real/US Dollar exchange rate. ${ }^{1}$ We put an emphasis in the comparison of the GARCH(p,q) with Gaussian and Student's t distribution for the errors, $\operatorname{EGARCH}(\mathrm{p}, \mathrm{q})$ with Gaussian errors, stationary AR(1)-SV estimated by quasi-maximum likelihood method and $\operatorname{SWARCH}(\mathrm{k}, \mathrm{q})$ with Gaussian and Student's t distribution for the errors.

This paper is organised as follows. In section 2 we present briefly the methods to estimate the volatility for the selected classes of models. Section 3 presents the best models selected according to the usual selection criteria. Section 4 compares the estimates of the volatilities according to the criteria proposed and the last section presents the conclusion.

\section{Methods to Estimate the Volatility}

Two classes of nonlinear models have been used to model the volatility of the returns. In both class the square of the volatility is given by the variance conditioned to the available information, but they use different information sets. In the first class, the Autoregresive Conditional Heteroskedasticity model, denoted by $\mathrm{ARCH}$, and

\footnotetext{
${ }^{1}$ The Cococa series is not repported because more than $10 \%$ of the observations were missing in trading days.
} 
introduced by Engle (1982) we use all the observed information up to the last observation. Later, several extensions were introduced, as the Generalised ARCH model, denoted by GARCH (Bollerslev, 1986), the ARCH model in the mean, denoted by ARCH-M (Engle \& Bollerslev, 1986), the Exponential GARCH model, denoted by EGARCH (Nelson, 1991), etc. In the second class the information is a non observable latent variable. This model, called Stochastic Volatility or Variance model, was introduced by Taylor (1980). Harvey et alii (1994) suggested the estimation of this model by quasimaximum likelihood method using Kalman filter and presented its properties. Inference and estimation by MCMC method can be found in Kim et alii (1998).

An extension of the ARCH class that allow for change in the variance regime was proposed by Cai (1994), Hamilton \& Susmel (1994) and Dueker (1997). In this model the time series can shift from one regime to another and this change follows some probabilistic law. Based on this information we can evaluate the posteriori probability of each regime, which can be incorporated in the prediction equation.

In the following we present all these approaches.

\subsection{GARCH and EGARCH models}

\subsubsection{Specification of the GARCH model}

Bollerslev (1986) introduced a generalisation of the ARCH model proposed by Engle (1982), named the Generalised ARCH (GARCH), which additionally contains lagged conditional variances. The data generating process for this type of model assume that a time series model denoted by $\left\{y_{t}\right\}_{t=1}^{\infty}$, which represents the returns of the series is related to an innovation process. Denoting this innovation process as $\left\{\varepsilon_{t}\right\}_{t=1}^{\infty}$. the $\operatorname{GARCH}(\mathrm{p}, \mathrm{q})$ model is defined by:

$$
y_{t}=u_{t}=\sqrt{h_{t}} \varepsilon_{t}
$$


P.L.Valls Pereira; L.K. Hotta; L.A.R. de Souza \& N.M.C.G. de Almeida

$$
h_{t}=\alpha_{0}+\sum_{i=1}^{q} \alpha_{i} u_{t-i}^{2}+\sum_{j=1}^{p} \beta_{j} h_{t-j}
$$

where $p \geq 0, q \geq 0, \alpha_{0}>0, \alpha_{i} \geq 0$, for $i=1, \ldots, q$ and $\beta_{j} \geq 0$ for $j=1, \ldots, p$. The innovations are assumed to follow a standard Gaussian distribution. Therefore, defining the information set as given by past information, i.e., $I_{t-1}=\left\{Y_{1}^{t-1}\right\}=\left\{y_{1}, \ldots, y_{t-1}\right\}$ the conditional distribution of the returns are normal with zero mean and variance $h_{t}$, i.e.,

$$
y_{t} \mid I_{t-1} \sim N\left(0, h_{t}\right)
$$

When $p=q=1$ we have the $\operatorname{GARCH}(1,1)$ model and $(2.2)$ reduce to:

$$
h_{t}=\alpha_{0}+\alpha_{1} u_{t-1}^{2}+\beta_{1} h_{t-1}
$$

For this model is possible to show that the returns are covariance stationary if $\alpha_{1}+\beta_{1}<1$, the unconditional mean is zero, the unconditional variance is given by $\operatorname{Var}\left(y_{t}\right)=E\left(y_{t}^{2}\right)=\frac{\alpha_{0}}{1-\alpha_{1}-\beta_{1}}$ and the excess of kurtosis larger than the normal distribution kurtosis.

\subsubsection{Identification}

Since the GARCH(1,1) model given by (2.1) and (2.4) can be rewritten as an $\operatorname{ARMA}(1,1)$ model with martingale difference disturbances, the identification process is based in the autocorrelation and partial autocorrelation structure of the square of the returns. Bollerslev (1986) showed that when returns follow a $\operatorname{GARCH}(p, q)$ process with orders larger than one than the square of the returns follow an $\operatorname{ARMA}(\max \{p, q\}, q)$ process, but the admissible parametric space smaller than the usual. Therefore we can use the BoxJenkins methodology in order to identify the orders of the process. 
According to Granger \& Newbold (1977) the sample autocorrelation and partial autocorrelation are consistent estimators and under the null hypotheses of non GARCH model we can use the asymptotic limits given by $\frac{2}{\sqrt{T}}$ (see Mc Leod \& Li (1983)).

\subsubsection{Estimation}

Assuming Gaussian innovations we can estimate the parameters maximising likelihood function. Weiss (1986) showed that this estimator is consistent and has asymptotically normal distribution. When the distribution of innovations is not Gaussian the quasi maximum likelihood estimator still has optimal properties when we correct the asymptotic variance, see Weiss (1986) or White (1982).

Notice that when the distribution of the innovations is known, for instance, the Student's t distribution used by Bollerslev (1987) or the generalised error distribution used by Nelson (1991), the maximum likelihood estimator can be easily obtained. Recently semiparametric models was used to estimate the $\varepsilon_{t}$ density (see Engle \& Gonzalez-Rivera, 1991).

\subsubsection{Diagnostic and model selection}

The model diagnostic can be done using two approaches. In the first approach we analyse the residuals and in the second one we can use model specification tests and/or we can use information criteria such as the Akaike (AIC) or Schwarz (BIC).

In the first case we evaluate the autocorrelation and partial autocorrelation functions of the square of the residuals and compare with the limits proposed by Li \& Mark (1994) in order to check whether 
the model was not able to explain all the nonlinear structure. This type of test is similar to the usual Portmanteau test.

In the second case Bollerslev (1986) proposed a Lagrange Multiplier test to test $\operatorname{GARCH}(\mathrm{p}, \mathrm{q})$ against the alternative hypothesis, GARCH $(\mathrm{p}, \mathrm{q}+\mathrm{r})$ with $r>0$. A difficult arising in constructing general tests for GARCH model comes from the fact that under the null hypothesis the parameters $\beta^{\prime}$ s are not identified. Lee (1991) showed that this difficult can be overcame using the fact that the LM tests for $\operatorname{GARCH}(p, q)$ can be taken as $\mathrm{LM}$ tests for $\mathrm{ARCH}(\mathrm{p}+\mathrm{q})$ models.

An alternative approach to compare models is through the use of Information criteria. For nonlinear models Tong (1990) called the attention to the fact that this criteria are adequate when comparing models in the same class and using the same estimation method and the same optimisation algorithm

\subsubsection{EGARCH model}

A strong criticism to the GARCH model is the symmetry of the response to the innovations. Nelson (1991) propose a new model, called EGARCH, with has asymmetric response to the innovations. Additionally it is not necessary to impose any restriction to the parameters. Its specification, assuming, standard normal disturbances is:

$$
\begin{aligned}
& y_{t}=u_{t}=\sqrt{h_{t}} \varepsilon_{t} \sim N I(0,1) \\
& \ln \left(h_{t}\right)=\alpha_{0}+\sum_{i=1}^{q} \alpha_{i} \varepsilon_{t-i}+\sum_{i=1}^{q} \gamma_{i}\left|\varepsilon_{t-i}\right|+\sum_{j=1}^{p} \beta_{j} \ln \left(h_{t-j}\right)
\end{aligned}
$$




\subsubsection{Prediction}

For the GARCH model the s-steps-ahead prediction of the conditional variance is given by:

$$
\begin{aligned}
h_{t+s \mid t} & =E\left(h_{t+s} \mid I_{t}\right) \\
& =E\left(\alpha_{0}+\alpha_{1} y_{t+s-1}^{2}+\beta_{1} h_{t+s-1 \mid t} \mid I_{t}\right) \\
& =\alpha_{0}+\alpha_{1} E\left(y_{t+s-1}^{2} \mid I_{t}\right)+\beta_{1} E\left(h_{t+s-1 \mid t} \mid I_{t}\right) \\
& =\alpha_{0}+\alpha_{1} h_{t+s-1 \mid t}+\beta_{1} h_{t+s-1 \mid t}
\end{aligned}
$$

which gives the following recursion:

$$
h_{t+s \mid t}=\alpha_{0}+\left(\alpha_{1}+\beta_{1}\right) h_{t+s-1 \mid t} \quad \forall s>0 .
$$

When the model is correctly specified the predictor proposed in (2.7) is optimal in the sense that minimises the MSE which is zero when $s=1$. In practice, however the MSE is not equal to zero for onestep-ahead prediction because the model is only an approximation and the parameters must be estimated.

\subsection{SWARCH model}

The models that introduced change in the regime of the conditional variance are known as SWARCH models. Hamilton \& Susmel (1994) presented one way to introduced this change in the regime in their study of the stock market. In their model there is only a change in the scale of the conditional variance when we change from one regime to another, i.e. we have:

$$
\begin{aligned}
y_{t} & =\mu+\phi y_{t-1}+u_{t} \\
u_{t} & =\sqrt{g_{S_{t}}} \widetilde{u}_{t} \\
\widetilde{u}_{t} & =\sqrt{h_{t}} \varepsilon_{t} \\
h_{t} & =\alpha_{0}+\sum_{i=1}^{q} \alpha_{i} \widetilde{u}_{t-i}^{2}
\end{aligned}
$$


where $\varepsilon_{t} \sim N I(0,1)$ and $S_{t}$ assume values equal to $1, \ldots k$, and $S_{t}$ follow a Markov Chain of order equal to one. When $k=2$ we have the following transition probabilities: $P\left\{S_{t}=1 \mid S_{t-1}=1\right\}=p$; $P\left\{S_{t}=2 \mid S_{t-1}=1\right\}=1-p ; P\left\{S_{t}=2 \mid S_{t-1}=2\right\}=q$ and $P\left\{S_{t}=\right.$ $\left.1 \mid S_{t-1}=2\right\}=1-q$.

Thus, the conditional variance follows an $\mathrm{ARCH}(\mathrm{q})$ process, where the variable $\widetilde{u}_{t}$ is multiplied by $\sqrt{g_{i}}$ when the process is in $\mathrm{i}$-th regime; $i=1, \cdots, k$. The basic idea underlying it is to consider only a change in the scale in the conditional variance process. This model is denoted as $\operatorname{SWARCH}(\mathrm{k}, \mathrm{q})$. The transition between the regimes is given by a first order Markov Chain. Hamilton \& Susmel (1994) used up to four regimes and considered the first regime the regime with smaller volatility, i.e. they consider $g_{1}=1$ and, $g_{j} \geq 1$ for $j=2, \ldots, k$, where $\mathrm{k}$ is the number of regimes.

Additionally, Hamilton \& Susmel (1994) also introduced in the specification of the conditional variance the leverage effect, where the impact of the innovations $\widetilde{u}_{t}$ depends on its sign. This type of behaviour occurs frequently in empirical time series where negative returns have more impact than the positive returns. Hamilton and Susmel proposed the following specification for the conditional variance:

$$
h_{t}=\alpha_{0}+\sum_{i=1}^{q} \alpha_{i} \widetilde{u}_{t-i}^{2}+\xi d_{t-1} \widetilde{u}_{t-1}^{2}
$$

where $d_{t-1}=1$ if $\widetilde{u}_{t-1} \leq 0$ and $d_{t-1}=0$ if $\widetilde{u}_{t-1}>0$, with $\xi>0$, and the model is denoted as SWARCH-L(k,q)

The normality assumption is not restrictive. Following Hamilton $\&$ Susmel (1994) we consider that the residuals $\varepsilon_{t}$ come from a Student's $t$ distribution with degree of freedom equal to $\eta$ (standardised in order to have unit variance). We have a Gaussian distribution when $\eta$ is large enough. 


\subsection{Stochastic volatility model}

Taylor (1980) presents an alternative to the ARCH type model. In his model the information set, which affects the conditional variance, is not given by the past information, but modelled by a non observed process. The model is specified as:

$$
\begin{aligned}
& y_{t}=\varepsilon_{t} \exp \left(\frac{h_{t}}{2}\right) \\
& h_{t}=\gamma_{0}+\gamma_{1} h_{t-1}+\eta_{t}
\end{aligned}
$$

where the component $h_{t}$ represents the flow of new information that arrives to the financial market. In general, this information has no regularity behaviour that can be modelled. Initially we are going to consider the case where $\varepsilon_{t}$ and $\eta_{t}$ are independent Gaussian processes with variances equal to one and $\sigma_{\eta}^{2}$, respectively. The main features of this type of model, called SV log-normal, model were discussed by Taylor (1980).

It is immediate to see that $y_{t}$ is stationary since it is the product of $\varepsilon_{t}$, which is stationary, with $h_{t}$, which is also stationary; that all the even moments exist when $h_{t}$ is stationary; that the odd moments are equal to zero; the kurtosis is larger than 3; that the tail of $y_{t}$ is heavier than the tail of the normal distribution and that the autocorrelation function of the square of the returns is given by:

$$
\rho_{y_{t}^{2}}(s) \cong \frac{\exp \left(\sigma_{h}^{2}\right)-1}{3 \exp \left(\sigma_{h}^{2}\right)-1} \gamma_{1}^{s} \text { for large } \gamma_{1}
$$

which is the autocorrelation function of an $\operatorname{ARMA}(1,1)$ process (see Herencia et alii, 1998). Thus, the SV model is similar to the $\operatorname{GARCH}(1,1)$ model in terms of the autocorrelation function when $\gamma_{1}$ is large. 
Another formulation equivalent to $(2.8-2.9)$ is:

$$
\begin{aligned}
& y_{t}=\sigma \varepsilon_{t} \exp \left(\frac{h_{t}}{2}\right) \\
& h_{t}=\gamma_{1} h_{t-1}+\eta_{t}
\end{aligned}
$$

Observe the when we take the logarithm of the square of (2.11), we have the linear process

$$
\ln \left(y_{t}^{2}\right)=\ln \left(\sigma^{2}\right)+h_{t}+\ln \left(\varepsilon_{t}^{2}\right)
$$

which is the sum of an $A R(1)$ process plus a white noise. Therefore the logarithm of the square of the returns can be represented by an $\operatorname{ARMA}(1,1)$ process.

A modification of (2.13) which simplifies the use of the Kalman filter is:

$$
\ln \left(y_{t}^{2}\right)=\kappa+h_{t}+\xi_{t}
$$

where $\xi_{t}=\ln \left(\varepsilon_{t}^{2}\right)-E\left(\ln \left(\varepsilon_{t}^{2}\right)\right)$ represent the irregular component, $\kappa \ln \left(\sigma^{2}\right)+E\left(\ln \left(\varepsilon_{t}^{2}\right)\right)$ is a constant to be estimated and $h_{t}$ is given by (2.12).

It is possible to have returns equal to zero in some observations and in this case the logarithmic transformation is not valid. In this case Fuller suggested the following transformation:

$$
\ln \left(\widetilde{y}_{t}^{2}\right)=\ln \left(y_{t}^{2}+c \widetilde{\sigma}_{y}^{2}\right)-\frac{c \tilde{\sigma}_{y}^{2}}{y_{t}^{2}+c \tilde{\sigma}_{y}^{2}}
$$

where $c$ is a constant to be selected, for instance 0.02 , and $\tilde{\sigma}_{y}^{2}$ is an estimate of the unconditional variance of the returns. Breidt \& Carriquirt (1996) showed that this transformation improves the properties of the quasi-maximum likelihood estimator and control the inliers. 
Quasi-Maximum Likelihood Estimator. Since the SV model given by (2.14) and (2.12) is in the state space representation, but with non-Gaussian disturbances the Kalman filter can be used to compute the quasi-likelihood, and in conjunction with an appropriate maximisation algorithm the quasi-maximum likelihood estimate. As a by-product the Kalman filter can also produce estimates of the component $h_{t}$. We can have the filtered estimate which uses only the past observations and the smoothed estimate which uses all the sample information.

The logarithm of the quasi-likelihood is given by:

$$
2 l(\theta ; y) \propto-\sum_{t=1}^{T} \ln \left(f_{t}\right)-\sum_{t=1}^{T} \frac{v_{t}^{2}}{f_{t}}
$$

where $v_{t}$ is the one-step-ahead prediction error and $f_{t}$ its variance.

The asymptotic properties of this estimator of $\theta$ are given by Harvey et alii (1994).

The estimate of the volatility is given by:

$$
\widehat{v o l}_{t}=\sigma_{*} \exp \left(\frac{h_{t \mid T}}{2}\right)
$$

where $h_{t \mid T}$ is the smoothed estimate of $h_{t}$ and $\sigma_{*}$ is the estimate of the sample standard deviation of the series adjusted by the heteroskedasticity, i.e.,

$$
\sigma_{*}=\sqrt{y_{t} \exp \left(-\frac{h_{t \mid T}}{2}\right)}
$$

Explanatory variables can be easily incorporated in the previous formulation writing $h_{t}^{+}=h_{t}+x_{t}^{\prime} \beta$ in the equations for the volatility given by (2.17), and for the standard deviation of the series adjusted for heteroskedasticity, given by (2.18), we must substitute $h_{t \mid T}$ by $h_{t \mid T}+x_{t}^{\prime} \beta$. 
P.L.Valls Pereira; L.K. Hotta; L.A.R. de Souza \& N.M.C.G. de Almeida

\section{Model Selection}

In this section we present the model selected for each of the series under study. We first present the models of the XARCH class, followed by the models of the SV class and lastly for the SWARCH class.

\subsection{GARCH, EGARCH models for the empirical series}

The identification and selection of the models presented were firstly based on the Akaike (AIC) and Schwarz (BIC) information criteria. However, not every model with the smallest AIC and BIC produced residuals with good quality. When the Ljung-Box's Q statistics indicated the presence of autocorrelation in the residuals or in the square of the residuals we looked among the models with good performance in terms of information criteria one that produced residuals with good quality. Additionally the models allowed for the existence of an AR(p) structure in the conditional mean of the process, and the order of the AR structure was chosen jointly with order of the XARCH structure. All the models were estimated using the sof tware GAUSS. The optimisation with restriction for the GARCH models was done with the CML program and the optimisation for the EGARCH model with the MAXLIK.

\subsubsection{Telebrás return series}

All the prices used in this paper are in US dollar. The Telebrás series has 989 daily price observations, from June 30, 1994 to July 1st, 1998. The identification and the model selection were based on 986 observations. We lost one observation because we work the returns and additionally another because we used a linear $\operatorname{AR}(2)$ filter. 
Figure 3.1 presents the plot of the returns of the logarithm of the series. We can see clearly two extreme values, one in the 171-Th. observation and the other in the 823-Th. observation, The first value occurs in March 10, 1995 and corresponds to the change in the target zone and the second to October 27, 1997 which corresponds to the beginning of the speculative attack in Asia.

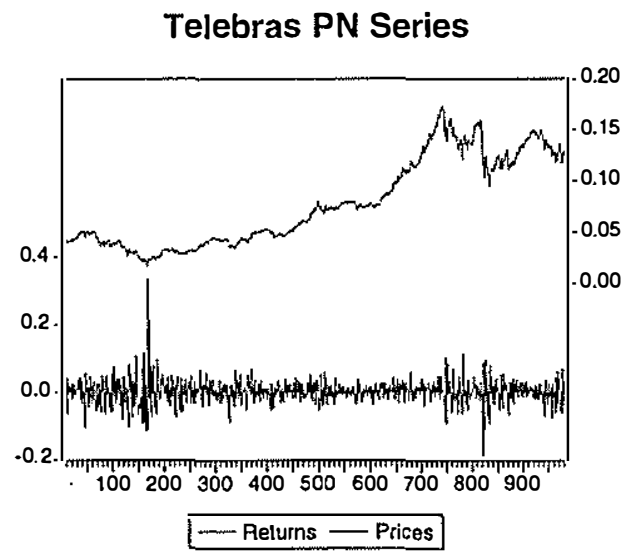

Figure 3.1

In the first case the volatility was already relatively large before the extreme observation and did not increase after the extreme observation. In the second case there was an increase in the volatility after the extreme observation showing that the two extreme observations have different effects. Using the prevalent classification in the literature we could classify the first observation as an additive outlier and the second as innovation outlier.

GARCH with Gaussian distribution. The best model selected by the Schwarz (BIC) criterion was the $\operatorname{GARCH}(1,1)$, and by the Akaike (AIC) criterion was the $\operatorname{GARCH}(3,2)$, both with only a constant in the mean (table 3.1). The statistics for the square of the residuals indicate that the dynamic specification of the $\operatorname{GARCH}(1,1)$ 
can be improved. In this case the alternative selected was the $\operatorname{GARCH}(3,2)$, which gives more flexibility in modelling the dynamic of the volatility. The estimated persistence by this new model decreased considerably, decreasing the unconditional variance.

\section{GARCH with Student's t distribution. Model GARCH(1,1)} was again selected by the BIC criterion. However, the Q statistics reject the hypothesis that the square of residuals are uncorrelated. The model t-GARCH $(3,2)$ with a single constant in the specification of the mean was able to overcome this problem. Similarly to the normal case there is a decrease in the estimate of the persistence when we fit the model with larger order, but the persistence is larger than in the normal distribution. The information criteria is larger for the t-GARCH models.

EGARCH-normal. The BIC criterion selected the EGARCH(1,1) model with only a constant in the mean and the AIC criterion the EGARCH $(1,1)$ model with AR(1) structure in the mean. We decided for the model with autoregressive structure because it was able to filter the autocorrelation of the returns in a parsimonious way. The EGARCH with and without the autoregressive structure was superior to the both GARCH models, with Gaussian or Student's. The EGARCH with smaller order - $(1,1)$ compared to $(3,2)$ of the GARCHs - filtered the autocorrelation of the square of the residuals in a satisfactory way.

Models with interventions. As mentioned previously there are two extreme observations (171-Th. and 823-Th.) in the Telebrás PN series. We decided to define two dummies variables in order to model their effect. For each observation we modelled the mean with a constant, without any autoregressive structure, and added a dummy variable (table 3.2). The main results after the inclusion 


\section{Alternative Models to Extract Asset Volatility}

Table 3.1

Goodness of Fit Statistics (Telebras)

\begin{tabular}{|c|c|c|c|c|c|c|}
\hline & GARCH $^{(1)}$ & & t-GARCH(2) & \multicolumn{3}{|c|}{ EGARCH $^{(3)}$} \\
\hline GARCH order & $(1,1)$ & $(3,2)$ & $(1,1)$ & $(3,2)$ & $(1,1)$ & $(1,1)$ \\
\hline $\mathrm{AR}$ order & 0 & 0 & 0 & 0 & 0 & 1 \\
\hline Persistence ${ }^{(x)}$ & 0.9701 & 0.9396 & 0.9801 & 0.9614 & 0.9263 & 0.9270 \\
\hline Degree of freedom & - & - & 9.4942 & 9.7331 & - & - \\
\hline Restrictions(boundery) & 1 & 1 & 1 & 2 & - & - \\
\hline Log-lik & 2141.72 & 2145.39 & 2154.26 & 2157.15 & 2158.04 & 2159.10 \\
\hline $\operatorname{AIC}^{(5)}$ & -4.3362 & -4.3375 & -4.3596 & -4.3593 & -4.3672 & -4.3673 \\
\hline $\mathrm{BIC}^{(6)}$ & -4.3163 & -4.3028 & -4.3347 & -4.3196 & -4.3424 & -4.3376 \\
\hline $\mathrm{Q}(6)\{\text { residuals }\}^{(7)}$ & 0.1331 & 0.1590 & 0.1570 & 0.1902 & 0.0787 & 0.3349 \\
\hline $\mathrm{Q}(12)\{$ residuals $\}$ & 0.3494 & 0.3442 & 0.3999 & 0.3923 & 0.1891 & 0.5251 \\
\hline $\mathrm{Q}(24)\{$ residuals $\}$ & 0.1982 & 0.1788 & 0.2262 & 0.1979 & 0.0782 & 0.1933 \\
\hline $\mathrm{Q}(36)\{$ residuals $\}$ & 0.5210 & 0.4849 & 0.5619 & 0.5191 & 0.3683 & 0.5875 \\
\hline $\mathrm{Q}(6)\left\{\right.$ residuals $\left.^{2}\right\}$ & $0.0368^{*}$ & 0.4020 & $0.0175^{*}$ & 0.4175 & 0.1069 & 0.1140 \\
\hline $\mathrm{Q}(12)\left\{\right.$ residuals $\left.{ }^{2}\right\}$ & 0.1070 & 0.5948 & 0.0645 & 0.6415 & 0.1303 & 0.1448 \\
\hline $\mathrm{Q}(24)\left\{\right.$ residuals $\left.{ }^{2}\right\}$ & 0.3819 & 0.7610 & 0.2692 & 0.7775 & 0.5013 & 0.5267 \\
\hline $\mathrm{Q}(36)\left\{\right.$ residuals $\left.^{2}\right\}$ & 0.4468 & 0.7281 & 0.3311 & 0.7503 & 0.4396 & 0.5026 \\
\hline
\end{tabular}

Notes:

*Indicates rejection of the null hypotheses of no correlation at $5 \%$ sigoificance.

**Indicates rejection of the null hypotheses of no correlation at $1 \%$ significance.

(1) The estimated model allow for an autoregressive $A R(p)$ structure in the mean always with a constant and a GARCH $(p, q)$ structure in the conditional variance. The following restrictions are considered on the parameters: $\alpha_{0}>0, \alpha_{i}, \beta_{j} \geq 0,(i=1, \ldots, q ; j=1, \ldots p), \sum \alpha_{i}+\sum \beta_{j} \leq 1$. The errors were considered as having normal distribution.

$y_{t}=\phi_{0}+\phi_{1} y_{t-1}+\ldots+\phi_{p} y_{t-p}+u_{t}, u_{t}=\sqrt{h_{t}} \varepsilon_{t}, \varepsilon_{t} \sim N(0,1)$

$h_{t}=\alpha_{0}+\sum_{i=1}^{q} \alpha_{i} u_{t-i}^{2}+\sum_{j=1}^{p} \beta_{j} h_{t-j}$.

(2) Similar to (1) but the with Student's t distribution for the errors, with the degree of freedom, with the restriction $\eta>2$, estimated jointly with the parameters.

$y_{t}=\phi_{0}+\phi_{1} y_{t-1}+\ldots+\phi_{p} y_{t-p}+u_{t}, u_{t}=\sqrt{h_{t}} \varepsilon_{t}, \varepsilon_{t} \sim t(\eta)$

$h_{t}=\alpha_{0}+\sum_{i=1}^{q} \alpha_{i} u_{t-i}^{2}+\sum_{j=1}^{p} \beta_{j} h_{t-j}$.

(3) Similar to (1) the estimated model allow for an autoregressive AR(p) structure in the mean always with a constant, but the AR(p) structure is now in the logarithm of the conditional variance allowing for asymmetric response to the innovations. It is not necessary to impose any restriction in the parameters and we assume that the errors follow a normal distribution.

$y_{t}=\phi_{0}+\phi_{1} y_{t-1}+\ldots+\phi_{p} y_{t-p}+u_{t}, u_{t}=\sqrt{h_{t}} \varepsilon_{t}, \varepsilon_{t} \sim N(0,1)$.

$\ln \left(h_{t}\right)=\alpha_{0}+\sum_{i=1}^{q} \alpha_{i} \varepsilon_{t_{-i}}+\sum_{i=1}^{q} \cdot \gamma_{i}\left|\varepsilon_{t-i}\right|+\sum_{j=1}^{p} \beta_{j} \ln \left(h_{t-j}\right)$.

(4) For the GARCH persistence is the sum of the coefficients $\alpha$ and $\beta$. For the EGARCH we present the sum of coefficients $\beta$, although it does not represent exactly the concept of persistence but an approxima. tion.

(5) $A I C=-\frac{2}{T}$ (Loglikel. $)+\frac{2 k}{T}$, where $\mathrm{T}$ is the number of observations and $\mathrm{k}$ the number of parameters.

(6) $B I C=-\frac{2}{T}($ Loglikel. $)+\frac{k \ln (T)}{\mathrm{T}}$, where $\mathrm{T}$ is the number of observations and $\mathrm{k}$ the number of parameters.

(7) p-values for the Ljung-Box $Q$ statistics. 
of the interventions are: a) large influence of these two observations in the variance parameters estimation ( $\alpha$ decreased of approximately one standard deviation and $\beta$ increased of approximately one standard deviation - tables 3.3 and 3.4 ) b) the square of the residuals did not present any autocorrelation for any of the three models, even with the small $(1,1)$ orders; c) Since the EGARCH model still has the best AIC and BIC criterion we could consider it the best model among the ARCH family to model the Telebrás $\mathrm{PN}$ returns series in the period under study, when we control by the 2 extreme observations.

Table 3.2

Goodness of Fit Statistics for the Model with Interventions (Telebrás)

\begin{tabular}{|c|c|c|c|}
\hline & GARCH & t-GARCH & EGARCH \\
\hline GARCH order & $(1,1)$ & $(1,1)$ & $(1,1)$ \\
\hline A R order & 0 & 0 & 0 \\
\hline Persistence & 0.9727 & 0.9824 & 0.9368 \\
\hline Degree of freedom & - & 12.1838 & - \\
\hline Restrictions(boundary) & 1 & 1 & - \\
\hline Log-Lik & 2159.71 & 2167.05 & 2170.17 \\
\hline $\mathrm{AIC}$ & -4.3686 & -4.3814 & -4.3878 \\
\hline $\mathrm{BIC}$ & -4.3388 & -4.3467 & -4.3530 \\
\hline $\mathrm{Q}(6)\{$ residuals $\}$ & 0.0659 & 0.0677 & $0.0278 *$ \\
\hline $\mathrm{Q}(12)\{$ residuals $\}$ & 0.2638 & 0.2815 & 0.1312 \\
\hline $\mathrm{Q}(24)\{$ residuals $\}$ & 0.1246 & 0.1281 & $0.0469 *$ \\
\hline $\mathrm{Q}(36)\{$ residuals $\}$ & 0.4684 & 0.4824 & 0.3193 \\
\hline $\mathrm{Q}(6)\left\{\right.$ residuals $\left.^{2}\right\}$ & 0.9608 & 0.9678 & 0.8439 \\
\hline $\mathrm{Q}(12)\left\{\right.$ residuals $\left.^{2}\right\}$ & 0.7625 & 0.7797 & 0.4462 \\
\hline $\mathrm{Q}(24)\left\{\right.$ residuals $\left.^{2}\right\}$ & 0.8845 & 0.8794 & 0.7828 \\
\hline $\mathrm{Q}(36)\left\{\right.$ residuals $\left.^{2}\right\}$ & 0.6157 & 0.6095 & 0.3654 \\
\hline
\end{tabular}

Note: For the above models the specification of the conditional mean is given by: $y_{t}=\phi_{0}+\delta_{1} I_{171}+\delta_{2} I_{823}+u_{t}, u_{t}=\sqrt{h_{t}} \varepsilon_{t}, \varepsilon_{t} \sim N(0,1)$. 
Alternative Models to Extract Asset Volatility

Table 3.3

Parameter Estimates for Model with Order(1,1) without Interventions (Telebrás)

\begin{tabular}{lcccccc}
\hline & Constant & $\alpha_{0}$ & $\alpha_{1}$ & $\beta_{1}$ & $\gamma$ & $\eta$ \\
\hline GARCH & 0.0029 & $10^{-6}$ & 0.1865 & 0.7836 & & \\
& $(0.0007)^{(1)}$ & (restr.) & $(0.0429)$ & $(0.0435)$ & & \\
t-GARCH & 0.0030 & $10^{-6}$ & 0.1709 & 0.8091 & & 9.4942 \\
& $(0.0007)$ & (restr.) & $(0.0367)$ & $(0.0371)$ & & $(2.5392)$ \\
EGARCH $^{(2)}$ & 0.0015 & -0.7431 & 0.2729 & 0.9270 & -0.1574 & \\
& $(0.0008)$ & $(0.1573)$ & $(0.0507)$ & $(0.0190)$ & $(0.0355)$ & \\
\hline
\end{tabular}

Notes:

(1) The statistics in brackets are the estimated standard deviation of the quasimaximum likelihood estimate.

(2) The results for the EGARCH are with the mean filter by an AR(1).

Table 3.4

Parameter Estimates for Model with $\operatorname{Order}(1,1)$ with Interventions (Telebrás)

\begin{tabular}{ccccccc}
\hline & Constant & $\alpha_{0}$ & $\alpha_{1}$ & $\beta_{1}$ & $\gamma$ & $\eta$ \\
\hline GARCH & 0.0027 & $10^{-6}$ & 0.1436 & 0.8291 & & \\
& $(0.0007)$ & (restr.) & $(0.0311)$ & $(0.0363)$ & & \\
t-GARCH & 0.0029 & $10^{-6}$ & 0.1469 & 0.8355 & & 12.1838 \\
& $(0.0007)$ & (restr.) & $(0.0307)$ & $(0.0332)$ & & $(4.2872)$ \\
EGARCH & 0.0018 & -0.6511 & 0.2431 & 0.9368 & -0.1208 & \\
& $(0.0007)$ & $(0.1416)$ & $(0.0412)$ & $(0.0175)$ & $(0.0312)$ & \\
\hline
\end{tabular}

\subsubsection{Cbond return series}

The Brazilian Brady bond return series, the Cbond, consists of 1066 daily observations from April 18, 1994 to July 1st, 1998. The 
first 2 observations was lost in the estimation of the AR(2) model and we ended with 1064 observations to estimate the volatility.

The figure 3.2 presents the return of the logarithm of the series. We can see clearly two group of extreme observations in the series, one in the 183-Th. and 186-Th. observations (January 9 and 12, 1995 - Mexico crisis) and another in the 897-Th., 898-Th. and 899Th. observations (October 27, 28 and 29, 1997 - speculative attack in Asia).

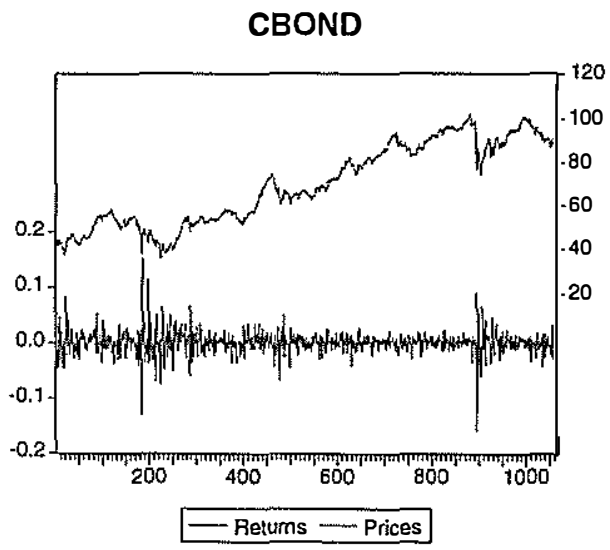

Figure 3.2

In both case the events increased considerably the volatility just after they happened. Therefore, if they are classified as outlier they are of the innovation type.

Table 3.5

Parameter Estimates for Model with Order(3,2) (Telebrás)

\begin{tabular}{ccccccccc}
\hline & Constant & $\alpha_{0}$ & $\alpha_{1}$ & $\alpha_{2}$ & $\beta_{1}$ & $\beta_{2}$ & $\beta_{3}$ & $\eta$ \\
\hline GARCH & 0.0029 & $10^{-6}$ & 0.2126 & 0.1624 & 0.0798 & 0.0613 & 0.4235 & \\
& $(0.0007)$ & (restr.) & $(0.0707)$ & $(0.0510)$ & $(0.1685)$ & $(0.2388)$ & $(0.3309)$ & \\
t-G_ARCH & 0.0030 & $10^{-6}$ & 0.1909 & 0.1647 & 0.0709 & 0 & 0.5348 & 9.7331 \\
& $(0.0007)$ & (restr.) & $(0.0591)$ & $(0.0474)$ & $(0.0989)$ & (restr.) & $(0.1143)$ & $(2.6369)$ \\
\hline
\end{tabular}


n-GARCH. The best model selected by the BIC criterion was the $\operatorname{GARCH}(1,1)$ with only a constant in the mean (table 3.6). The Ljung-Box $Q$ statistics does not detects any autocorrelation in the residuals. The second best model selected by the $\mathrm{BIC}$ criterion has an $A R(2)$ structure in the mean. The null hypothesis of no autocorrelation is not rejected up to the $12-\mathrm{Th}$. lag at $5 \%$ significance and models with larger order only brings marginal improvements. The $\mathrm{Q}$ statistics for the 12-Th. lag of the square of the residuals indicates a possible structure left in the variance. However, they can only be corrected by very large orders and are heavily penalised by the information criteria. For parsimonious reason we decided for the $\operatorname{GARCH}(1,1)$ model with $\mathrm{AR}(2)$ structure in the mean. The persistence decreased slightly with the filter in the mean reducing the unconditional variance.

Table 3.6

Goodness of Fit Statistics (Cbond)

\begin{tabular}{|c|c|c|c|c|c|c|}
\hline & \multicolumn{2}{|c|}{ GARCH } & \multicolumn{2}{|c|}{ t-GARCH } & \multicolumn{2}{|c|}{ EGARCH } \\
\hline GARCH order & $(1,1)$ & $(1,1)$ & $(1,1)$ & $(1,1)$ & $(1,1)$ & $(1,1)$ \\
\hline AR order & 0 & 2 & 0 & 2 & 0 & 1 \\
\hline Persistence & 0.9885 & 0.9879 & 0.9863 & 0.9862 & 0.9364 & 0.9362 \\
\hline Degree of freedom & - & - & 4.3654 & 4.3441 & - & - \\
\hline Restrictions (boundary) & 1 & 1 & 1 & 1 & - & - \\
\hline Log-likelihood & 2941.06 & 2941.45 & 3007.61 & 3007.76 & 2960.85 & 2961.03 \\
\hline AIC & -5.5208 & -5.5177 & -5.6440 & -5.6405 & -5.5561 & -5.5546 \\
\hline $\mathrm{BIC}$ & -5.5021 & -5.4897 & -5.6206 & -5.6078 & -5.5328 & -5.5265 \\
\hline $\mathrm{Q}(6)\{$ residuals $\}$ & 0.2780 & 0.4253 & 0.2509 & 0.2507 & 0.3310 & 0.4967 \\
\hline $\mathrm{Q}(12)\{$ residuals $\}$ & $0.0460 *$ & 0.0804 & $0.0270^{*}$ & $0.0274^{*}$ & 0.0677 & 0.1122 \\
\hline $\mathrm{Q}(24)\{$ residuals $\}$ & 0.1778 & 0.2610 & 0.1174 & 0.1159 & 0.2290 & 0.3069 \\
\hline $\mathrm{Q}(36)\{$ residuals $\}$ & 0.3272 & 0.4230 & 0.2517 & 0.2488 & 0.3222 & 0.3962 \\
\hline $\mathrm{Q}(6)\left\{\right.$ residuals $\left.^{2}\right\}$ & 0.3834 & 0.3863 & 0.1339 & 0.1277 & 0.6428 & 0.6339 \\
\hline $\mathrm{Q}(12)\left\{\right.$ residuals $\left.^{2}\right\}$ & $0.0319 *$ & $0.0376^{*}$ & $0.0097 * *$ & $0.0095^{* *}$ & 0.1771 & 0.1754 \\
\hline $\mathrm{Q}(24)\left\{\right.$ residuals $\left.^{2}\right\}$ & 0.3690 & 0.3957 & 0.2169 & 0.2160 & 0.6860 & 0.6807 \\
\hline $\mathrm{Q}(36)\left\{\right.$ residuals $\left.^{2}\right\}$ & 0.7496 & 0.7643 & 0.6709 & 0.6710 & 0.9218 & 0.9201 \\
\hline
\end{tabular}


t-GARCH. The model selected by both information criteria was the GARCH $(1,1)$ only with a constant in the mean. However, the Q statistics detected a dynamic structure in the mean and in the conditional variance. We ended opting for an $\mathrm{AR}(2)$ structure as a trade-off between information criteria and the performance of the residuals analysed by the Q-statistics. GARCH models with larger order have worse performance in terms of information criteria with only a marginal improvement in the quality of the residuals. The t-GARCH has a clear superior performance in terms of information criteria and has smaller persistence than the n-GARCH models.

n-EGARCH. The model selected by both information criteria was the $\operatorname{EGARCH}(1,1)$ only with a constant in the mean. However we included an AR(1) structure in the mean in order to explain the autocorrelation in the residuals detected by the $\mathrm{Q}$ statistics. After the inclusion of this structure the performance of this EGARCH model was superior to the GARCH models in terms of the $\mathrm{Q}$ statistics. Probably the heavier tail of the Student's t distribution is more adequate for the returns, but the EGARCH is more appropriate to model the dynamic structure.

\section{Table 3.7}

Parameter Estimates for Model with a Constant (Cbond)

\begin{tabular}{ccccccc}
\hline & Constant & $\alpha_{0}$ & $\alpha_{1}$ & $\beta_{1}$ & $\gamma$ & $\eta$ \\
\hline GARCH & 0.0014 & $10^{-6}$ & 0.1890 & 0.7995 & & \\
& $(0.0005)$ & (restr.) & $(0.0862)$ & $(0.0710)$ & & \\
t-GARCH & 0.0016 & $10^{-6}$ & 0.0981 & 0.8881 & & 4.3654 \\
& $(0.0004)$ & (restr.) & $(0.0255)$ & $(0.0233)$ & & $(0.6094)$ \\
EGARCH & 0.0008 & -0.7502 & 0.2909 & 0.9364 & -0.1519 & \\
& $(0.0004)$ & $(0.2580)$ & $(0.0725)$ & $(0.0262)$ & $(0.0503)$ & \\
\hline
\end{tabular}




\subsubsection{Real/US dollar exchange rate return series}

The Brazilian Real/US dollar exchange rate series have 997 daily observations from June 30, 1994 to July 1st, 1998. The sample used in all the estimation has 994 logarithm returns. We multiplied the returns by 100 in order to avoid numerical problems due to small values.

Figure 3.3 presents the plot of the Real/US Dollar exchange rate and the correspondent returns since the beginning of the Real Plan until July 1998. There is clearly one behaviour until the 250Th. observation. ${ }^{2}$ and another afterwards and any model which fail to take this fact into account will have some lack of fit problem. For instance, if we fit a GARCH model for all the series we certainly will have a model which underestimate the unconditional variance in the first part and overestimate in the second part.

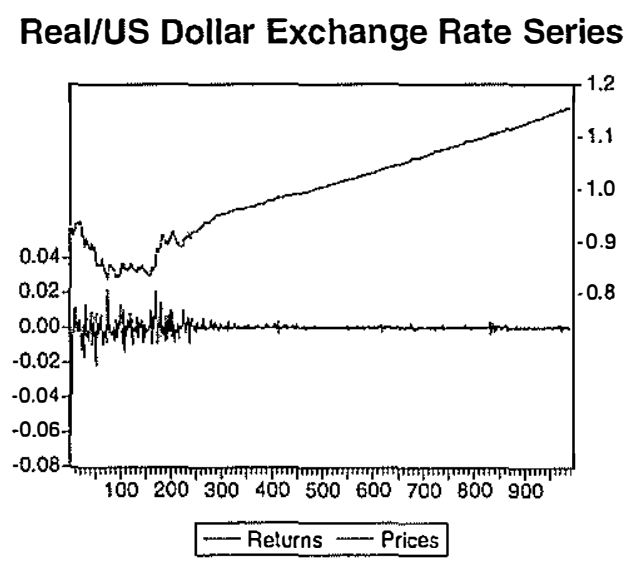

Figure 3.3

One way to overcome this problem is to include a dummy variable in the specification of the mean and of the conditional variance. This

\footnotetext{
${ }^{2} \mathrm{~A}$ variance stability test was carried out and the result of this test indicates that this is the correct point to introduce the dummy variable.
} 
variable is equal to one until the $250-\mathrm{Th}$. observation (June 30,1995$)$, and $\mathbf{0}$ afterwards, allowing for different models for the mean and the variance in each period.

n-GARCH. The model selected by the BIC criterion was the $\operatorname{GARCH}(3,1)$ with dummy in the specification of the conditional variance and constant plus dummy and $A R(2)$ in the mean (table 3.8). The $Q$ statistics detected autocorrelation in both residuals and square of the residuals. The second best model, $\operatorname{GARCH}(2,1)-$ $\mathrm{AR}(2)$ with in the conditional variance presents the same problem. Since in order to decrease this problem is necessary to use too large orders, penalising excessively the information criteria without any significative difference in the estimates of the conditional variance, we choose $\operatorname{GARCH}(3,1)-\mathrm{AR}(2)$ model.

t-GARCH. The BIC criterion selected the $\operatorname{GARCH}(1,1)$ with dummy in the conditional variance and constant plus dummy in the mean while the AIC selected the same model except for an additional AR(2) structure in the mean. The $\mathrm{Q}$ statistics reject the null hypothesis of no serial correlation in the square of the residuals after the 16-Th. lag due to an unexplained large correlation in this lag. We decided not use order larger than 2 in the autoregressive structure because larger orders penalised the information criteria without improving significantly the results.

This t-GARCH(1,1) with AR(2) structure has better AIC and BIC criteria than the previous n-GARCH(3,1) model which was previously selected by the information criteria among the GARCH model with normal disturbances. The model with Students't distribution also has better performance in term of the $\mathrm{Q}$ statistics. The persistence is larger in the Students't distribution model and the estimated degree of freedom is small implying a heavy tail. This is probably due to the larger dispersion found in the first part of the series. 
Alternative Models to Extract Asset Volatility

Table 3.8

Goodness of Fit Statistics (Exchange Rate)

\begin{tabular}{|c|c|c|c|c|}
\hline & \multicolumn{2}{|c|}{$\mathrm{GARCH}^{(1)}$} & \multicolumn{2}{|c|}{ t-GARCH(2) } \\
\hline GARCH order & $(3,1)$ & $(2,1)$ & $(1,1)$ & $(1,1)$ \\
\hline AR order & 2 & 2 & 0 & 2 \\
\hline Persistence & 0.9543 & 0.9619 & 0.9757 & 0.9824 \\
\hline degree of freedom & - & - & 3.0390 & 3.0477 \\
\hline Restrictions(boundary) & 1 & 0 & 0 & 0 \\
\hline Log-Lik & 832.53 & 824.24 & 896.29 & 899.51 \\
\hline $\mathrm{AIC}$ & -1.6550 & -1.6403 & -1.7893 & -1.7918 \\
\hline $\mathrm{BIC}$ & -1.6057 & -1.5959 & -1.7548 & -1.7474 \\
\hline $\mathrm{Q}(6)\{$ residuals $\}$ & 0.1914 & 0.3350 & 0.0333 & 0.3298 \\
\hline $\mathrm{Q}(12)\{$ residuals $\}$ & 0.0273 & 0.0545 & 0.0057 & 0.0370 \\
\hline $\mathrm{Q}(24)\{$ residuals $\}$ & 0.0070 & 0.0156 & 0.0016 & 0.0044 \\
\hline $\mathrm{Q}(36)\{$ residuals $\}$ & 0.0401 & 0.0832 & 0.0162 & 0.0333 \\
\hline $\mathrm{Q}(6)\left\{\right.$ residuals $\left.^{2}\right\}$ & 0.0396 & 0.0204 & 0.9218 & 0.9141 \\
\hline $\mathrm{Q}(12)\left\{\right.$ residuals $\left.^{2}\right\}$ & 0.1100 & 0.0689 & 0.9946 & 0.9909 \\
\hline $\mathrm{Q}(24)\left\{\right.$ residuals $\left.^{2}\right\}$ & 0.1699 & 0.0522 & 0.0000 & 0.0000 \\
\hline $\mathrm{Q}(36)\left\{\right.$ residuals $\left.^{2}\right\}$ & 0.1329 & 0.0514 & 0.0000 & 0.0000 \\
\hline
\end{tabular}

Notes:

(1) The estimated model allow for an autoregressive AR(p) structure in the mean always with constant and a dummy variable to model the structural break and a $\operatorname{GARCH}(p, q)$ structure in the conditional variance also with dummy variable to model the structural break. The following restrictions are considered on the parameters: $\alpha_{0}>0, \delta_{v} \geq 0, \alpha_{i}, \beta_{j} \geq 0,\left(i=1, \ldots, q_{j} j=1, \ldots p\right), \sum \alpha_{i}+\sum \beta_{j} \leq 1$. The errors were considered as having normal distribution.

$y_{t}=\delta_{m} d_{t}+\phi_{0}+\phi_{1} y_{t-1}+\ldots+\phi_{p} y_{t-p}+u_{t}, u_{t}=\sqrt{h_{t}} \varepsilon_{t}, \varepsilon_{t} \sim N(0,1)$

$h_{t}=\delta_{v} d_{i}+\alpha_{0}+\sum_{i=1}^{q} \alpha_{i} u_{t-i}^{2}+\sum_{j=1}^{p} \beta_{j} h_{t-j}$

(2) Similar to (11) but the with Student's t distribution for the errors, with the degree of freedom, with the restriction $\eta>2$, estimated jointly with the parameters.

$y_{t}=\delta_{m} d_{t}+\phi_{0}+\phi_{1} y_{t-1}+\ldots+\phi_{p} y_{t-p}+u_{t}, u_{t}=\sqrt{h_{t}} \varepsilon_{t}, \varepsilon_{t} \sim t(\eta)$

$h_{t}=\delta_{1} d_{t}+\alpha_{0}+\sum_{i=1}^{q} \alpha_{i} u_{t-i}^{2}+\sum_{j=1}^{p} \beta_{j} h_{t-j}$.

\subsection{Stochastic volatility model}

The Stochastic Volatility models (SV) were estimated by the quasi-maximum likelihood method. 
P.L.Valls Pereira; L.K. Hotta; L.A.R. de Souza \& N.M.C.G. de Almeida

\subsubsection{Estimation of Telebrás series by quasi-maximum like- lihood method}

The SV models estimated for the Telebrás return series were:

- Model I: simple AR(1)-SV, i.e. given by (2.14 and 2.12);

- Model II: AR(1)-SV with adjustment for days of week in the variance;

- Model III: AR(1)-SV with dummies in the 171-Th. and 823-Th. observations, which correspond to the change in the target zone and the Asian crisis.

Table 9

Parameter Estimates for Model with AR(2) and Dummy in Mean and Variance (Exchange Rate)

\begin{tabular}{llllllllll}
\hline & Constant & $\delta_{m}$ & $\alpha_{0}$ & $\alpha_{1}$ & $\beta_{1}$ & $\beta_{2}$ & $\beta_{3}$ & $\delta_{v}$ & $\eta$ \\
\hline n-GARCH-AR(2) & 0.0324 & -0.0208 & 0.0003 & 0.2839 & 0.3607 & 0 & 0.3097 & 0.0261 & \\
& $(0.0022)$ & $(0.0379)$ & $(0.0001)$ & $(0.0969)$ & $(0.1063)$ & $($ restr.) & $(0.1115)$ & $(0.0151)$ \\
n-GARCH-AR(2) & 0.0319 & -0.0287 & 0.0002 & 0.2363 & 0.4502 & 0.2754 & & 0.0227 & \\
& $(0.0023)$ & $(0.0382)$ & $(0.0001)$ & $(0.1134)$ & $(0.1264)$ & $(0.1555)$ & & $(0.0138)$ & \\
t-GARCH & 0.0267 & -0.0405 & 0.0007 & 0.4153 & 0.5671 & & & 0.1011 & 3.0477 \\
& $(0.0023)$ & $(0.0309)$ & $(0.0003)$ & $(0.1096)$ & $(0.1018)$ & & & $(0,0490)$ & $(0,1011)$ \\
\hline
\end{tabular}

Table 3.10 presents the parameters estimates and some statistics to measure the quality of the adjustment.

The AIC criterion selected Model III as the best one while BIC criterion selected Model I. The estimated persistence in the first two models are equal while in the third model is a slightly larger. The week days dummies of Model II are statistically significant but there is no statistical indication of the presence of the effect of week days. Both outliers of Model III are statistically significant. 
Alternative Models to Extract Asset Volatility

Table 3.10

Goodness of Fit Statistics (Telebrás)

\begin{tabular}{|c|c|c|c|}
\hline & Model I & Model II & Model III \\
\hline Log-Lik ${ }^{1}$ & -1910.79 & -1909.26 & -1905.45 \\
\hline P.E.V. ${ }^{2}$ & 2.8346 & 2.8258 & 2.8040 \\
\hline$\sigma_{\xi}^{2}$ & $\begin{array}{c}1.5974 \\
{[1.0000]^{3}}\end{array}$ & $\begin{array}{c}1.5984 \\
{[1.0000]}\end{array}$ & $\begin{array}{l}1.5954 \\
{[1.0000]}\end{array}$ \\
\hline$\sigma_{\eta}^{2}$ & $\begin{array}{r}0.2016 \\
{[0.1262]}\end{array}$ & $\begin{array}{c}0.2014 \\
{[0.1260]}\end{array}$ & $\begin{array}{l}0.1889 \\
{[0.1184]}\end{array}$ \\
\hline$\gamma_{1}$ & 0.9765 & 0.9765 & 0.9783 \\
\hline Monday & & $\begin{array}{c}-8.2750 \\
(0.2874)^{4}\end{array}$ & \\
\hline Tuesday & & $\begin{array}{l}-8.0774 \\
(0.2874)\end{array}$ & \\
\hline Wednesday & & $\begin{array}{c}-8.2747 \\
(0.2876)\end{array}$ & \\
\hline Thursday & & $\begin{array}{c}-8.3285 \\
(0.2883)\end{array}$ & \\
\hline Friday & & $\begin{array}{r}-8.2686 \\
(0.2874)\end{array}$ & \\
\hline i171 & & & $\begin{array}{c}4.0609 \\
(1.6444)\end{array}$ \\
\hline i823 & & & $\begin{array}{c}3.5786 \\
(1.6444)\end{array}$ \\
\hline $\begin{array}{l}\text { AIC } \\
\text { BIC }\end{array}$ & $\begin{array}{l}3.8879 \\
3.8826\end{array}$ & $\begin{array}{l}3.8929 \\
3.9327\end{array}$ & $\begin{array}{l}3.8812 \\
3.9109\end{array}$ \\
\hline $\mathrm{Q}(6)\{$ residuals $\}$ & $(0.1392)^{5}$ & $(0.1592)$ & $(0.0723)$ \\
\hline$Q(12)\{$ residuals $\}$ & $(0.3685)$ & $(0.3825)$ & $(0.3096)$ \\
\hline $\mathrm{Q}(24)\{$ residuals $\}$ & $(0.2547)$ & $(0.2225)$ & $(0.1734)$ \\
\hline $\mathrm{Q}(36)\{$ residuals & $(0.5956)$ & $(0.5523)$ & $(0.5117)$ \\
\hline $\mathrm{Q}(6)\left\{\right.$ residuals $\left.^{2}\right\}$ & $(0.2850)$ & $(0.3350)$ & $(0.1762)$ \\
\hline $\mathrm{Q}(12)\left\{\right.$ residuals $\left.^{2}\right\}$ & $(0.4294)$ & $(0.4419)$ & $(0.1372)$ \\
\hline $\mathrm{Q}(24)\left\{\right.$ residuals $\left.^{2}\right\}$ & $(0.8111)$ & $(0.7790)$ & $(0.4965)$ \\
\hline $\mathrm{Q}(36)\left\{\right.$ residuals $\left.^{2}\right\}$ & $(0.5236)$ & $(0.5221)$ & $(0.0630)$ \\
\hline
\end{tabular}

Notes:

(1) Log-Lik represents the log- likelihood.

(2) P.E.V. represents prediction error variance.

(3) The values in parentheses is the rate between the component variance and the largest variance among the components.

(4) The values in brackets are the estimated standard deviation of the estimates.

(5) For the $Q$ statistics the values in brackets are the p-values. 
The Q statistics does not reject the hypothesis of no correlation when applied to the residuals and to the square of the residuals for all lags and models. This indicates that the model was able to explain the nonlinearity,

\subsubsection{Quasi-maximum likelihood estimation of the Cbonds return series}

The stochastic volatility models estimated for the Cbond return series were:

- Model I: usual AR(1)-SV, i.e., given by (2.14 and 2.12);

- Model II: AR(1)-SV with adjustment for week days in the variance;

Table 3.11 presents the parameters estimate and the quality of adjustment statistics.

According to the information criteria the best model is model I. Observe that the persistence in both model are approximately equal. The dummies of the weekdays in model II are statistically significative but the difference are not, favouring model I, which does not consider the weekdays effect. The $\mathrm{Q}$ statistics does not reject the null hypothesis for any lag when applied to the residuals. However, when the test is applied to the square of the residuals the null hypothesis of non correlation is rejected indicating that some non linearity remained.

\subsubsection{Quasi-maximum likelihood estimation for the returns of the Real/US dollar exchange rate series}

The stochastic volatility models estimated for the exchange rate Real/US Dollar were: 
- Model I: AR(1)-SV model with local level ${ }^{3}$ instead of a constant;

- Model II: AR(1)-SV dummy for the first 250 observations.

\section{Table 3.11}

Goodness of Fit Statistics (Cbond)

\begin{tabular}{|c|c|c|}
\hline & Model I & Model II \\
\hline Log-Lik ${ }^{1}$ & -2138.02 & -2136.08 \\
\hline P.E.V. ${ }^{2}$ & 3.2698 & 3.2579 \\
\hline$\sigma_{\xi}^{2}$ & $\begin{array}{c}1.7394 \\
{[1.0000]}\end{array}$ & $\begin{array}{c}1.7398 \\
{[1.0000]}\end{array}$ \\
\hline$\sigma_{\eta}^{2}$ & $\begin{array}{c}0.1629 \\
{[0.0937]}\end{array}$ & $\begin{array}{c}0.1628 \\
{[0.0936]}\end{array}$ \\
\hline$\gamma_{1}$ & 0.9824 & 0.9825 \\
\hline Monday & & $\begin{array}{c}-9.7313 \\
(0.2989)\end{array}$ \\
\hline Tuesday & & $\begin{array}{c}-9.5232 \\
(0.2973)\end{array}$ \\
\hline Wednesday & & $\begin{array}{l}-9.4979 \\
(0.2975)\end{array}$ \\
\hline Thursday & & $\begin{array}{c}-9.7334 \\
(0.2974)\end{array}$ \\
\hline Friday & & $\begin{array}{c}-9.6803 \\
(0.2977)\end{array}$ \\
\hline AIC & 4.0301 & 4.0340 \\
\hline $\mathrm{BIC}$ & 4.0488 & 4.0714 \\
\hline $\mathrm{Q}(6)\{$ residuals $\}$ & $(0.5275)$ & $(0.5475)$ \\
\hline $\mathrm{Q}(12)\{$ residuals $\}$ & $(0.4432)$ & $(0.4163)$ \\
\hline $\mathrm{Q}(24)$ residuals & $(0.5453)$ & $(0.4796)$ \\
\hline $\mathrm{Q}(36)\{$ residuals & $(0.5691)$ & $(0.5276)$ \\
\hline $\mathrm{Q}(6)\left\{\right.$ residuals $\left.^{2}\right\}$ & $(0.0000)^{* *}$ & $(0.0000)^{* *}$ \\
\hline $\mathrm{Q}(12)\left\{\right.$ residuals $\left.^{2}\right\}$ & $(0.0000)^{* *}$ & $(0.0000)^{* *}$ \\
\hline $\mathrm{Q}(24)\left\{\right.$ residuals $\left.^{2}\right\}$ & $(0.0000)^{* *}$ & $(0.0000)^{* *}$ \\
\hline $\mathrm{Q}(36)\left\{\right.$ residuals $\left.^{2}\right\}$ & $(0.0000)^{* *}$ & $(0.0008)^{* *}$ \\
\hline
\end{tabular}

\footnotetext{
${ }^{3}$ In this model $\kappa$ was allowed to follow a random walk. The rationality is to allow the mean
} and unconditional variance to change slowly. 
P.L.Valls Pereira; L.K. Hotta; L.A.R. de Souza \& N.M.C.G. de Almeida

Table 3.12 presents the parameters estimates with some quality of adjustment statistics.

Table 3.12

Goodness of Fit Statistics (Exchange Rate)

\begin{tabular}{|c|c|c|}
\hline & Model I & Model II \\
\hline Log-Lik ${ }^{1}$ & -1764.60 & -1758.78 \\
\hline $\begin{array}{l}\text { P.E.V. } \\
\sigma_{\xi}^{2}\end{array}$ & $\begin{array}{c}2.0467 \\
1.2844 \\
{[1.0000]}\end{array}$ & $\begin{array}{c}2.0228 \\
1.2894 \\
{[1.0000]}\end{array}$ \\
\hline$\sigma_{\eta}^{2}$ & $\begin{array}{c}0.4273 \\
{[0.3327]}\end{array}$ & $\begin{array}{c}0.4572 \\
{[0.3545]}\end{array}$ \\
\hline$\sigma_{\zeta}^{2}$ & $\begin{array}{c}0.0911 \\
{[0.0709]}\end{array}$ & \\
\hline $\begin{array}{l}\gamma_{1} \\
\text { D250 }\end{array}$ & 0.6714 & $\begin{array}{c}0.7202 \\
3.3638 \\
(0.1521)\end{array}$ \\
\hline $\begin{array}{l}\text { AIC } \\
\text { BIC } \\
\text { Q }(6)\{\text { residuals }\}\end{array}$ & $\begin{array}{c}3.5550 \\
3.5749 \\
(0.0234)^{*}\end{array}$ & $\begin{array}{l}3.5453 \\
3.5699 \\
(0.0102)^{*}\end{array}$ \\
\hline $\mathrm{Q}(12)\{$ residuals $\}$ & $(0.1281)$ & $(0.1021)$ \\
\hline $\mathrm{Q}(24)\{$ residuals $\}$ & $(0.0000)^{* *}$ & $(0.0000)^{* *}$ \\
\hline $\mathrm{Q}(36)\{$ residuals $\}$ & $(0.0001)^{* *}$ & $(0.0552)$ \\
\hline $\mathrm{Q}(6)\left\{\right.$ residuals $\left.^{2}\right\}$ & $(0.3672)$ & $(0.0000)^{* *}$ \\
\hline $\mathrm{Q}(12)\left\{\right.$ residuals $\left.^{2}\right\}$ & $(0.0141)^{*}$ & $(0.0000)^{* *}$ \\
\hline $\mathrm{Q}(24)\left\{\right.$ residuals $\left.^{2}\right\}$ & $(0.0000)^{* *}$ & $(0.0000)^{* *}$ \\
\hline $\mathrm{Q}(36)\left\{\right.$ residuals $\left.^{2}\right\}$ & $(0.0000)^{* *}$ & $(0.0000)^{* *}$ \\
\hline
\end{tabular}

Model II is the best according to both information criteria. Observe that the persistence is small in both models. In model II the dummy which control for the change in the mean and in the conditional variance was statistically significative. 
According to the $\mathrm{Q}$ statistic for the residuals, only for lag 12 for both models and lag 36 for Model II, the null hypothesis of non correlation is not rejected. The results for the square of the residuals show that the models were not able to filter all the non linearity in the series.

\subsection{SWARCH Models}

We followed Hamilton and Susmel (1994) work and fitted SWARCH models with 1 and 2 lags in the ARCH structure, with Gaussian and Student-t disturbances, with 2 and 3 regimes, with and without leverage effect according to the model presented in section 2.2. We also introduced a constant in every model and an autoregressive structure of order one or two in the mean process of some models. All the models were estimated using programs obtained from Hamilton \& Susmel (1994) and the OPTIMUM program from GAUSS.

\subsubsection{Telebrás return series}

The results for Telebrás series obtained for the SWARCH models selected by the AIC and BIC criteria are presented in table 3.13. The best model according to both criteria was the n-SWARCH-L $(2,2)$ model. Restricting to the 3 regimes models both criteria selected the n-SWARCH-L $(3,2)$ model The introduction of the autoregressive structure in the mean did not improved any of the statistical criteria. The Q-statistic did not detect significant correlation in the mean and in the variance at $5 \%$ level.

The estimate of the n-SWARCH-L $(2,2)$ model, which was selected by the BIC criterion is given in the following, with estimated 
standard error of the estimate in parentheses:

$$
\begin{aligned}
y_{t} & =\underset{(0.000727)}{0.002978+u_{t}} \\
u_{t} & =\sqrt{g_{S_{t}}} \widetilde{u}_{t} \text { where } S_{t}=1,2 \\
u_{t}^{*} & =\sqrt{h_{t}} v_{t}
\end{aligned}
$$

where $v_{t} \sim N(0,1)$ and $h_{t}$ is given by:

$$
h_{t}=\underset{\left(3.098 \times 10^{-5}\right)}{0.0002317}+\underset{(0.0388)}{7.433} \times 10^{-11} \widetilde{u}_{t-1}^{2}+\underset{(0.0495)}{0.2104 \widetilde{u}_{t-2}^{2}}+\underset{(0.0839)}{0.3203 d_{t-1}} \widetilde{u}_{t-1}^{2}
$$

where

$$
d_{t-1}=\left\{\begin{array}{ll}
1 & \text { if } u_{t-1} \leq 0 \\
0 & \text { if } u_{t-1}>0,
\end{array} \quad g_{1}=1, \quad g_{2}=3.7984\right.
$$

and transition matrix given by:

$$
P=\left[\begin{array}{ll}
0.979707 & 0.016818 \\
0.020293 & 0.983182
\end{array}\right]
$$

The values $\mathrm{p}_{i j}$ are the transition probability from regime $i$ to regime $j$. We can observe the probability of the series remain in the same regime is large. The probability of changing from one regime to another is very small with the expected time in regimes 1 and 2 are about 49 and 60 days, respectively. ${ }^{4}$ The scale factor that multiply the volatility in the second regime is $\sqrt{3.7983912}$, i.e. the volatility in the second regime is about twice the volatility in the first regime. The effect of the asymmetry is significative and in every model improved

\footnotetext{
${ }^{4}$ The expected time in a regime is computed by $\left(1-p_{i}\right)^{-1}$.
} 
the information criteria, i.e. for the Telebrás series the volatility always increase considerably when the return is negative. This type of behaviour was first observed by Black (1976).

Table 3.13

Goodness of Fit Statistics (Telebrás)

\begin{tabular}{|c|c|c|}
\hline & n-SWARCH-L(2,2) & n-SWARCH-L $(3,2)$ \\
\hline $\begin{array}{l}\text { AR order } \\
\text { Degree of freedom }\end{array}$ & 0 & 0 \\
\hline Log-Lik & 2154.9264 & 2156.7223 \\
\hline $\mathrm{AIC}$ & -4.3592414 & -4.3567966 \\
\hline $\mathrm{BIC}$ & -4.3195043 & -4.3021579 \\
\hline $\mathrm{Q}(6)\{$ residuals $\}$ & 0.0792 & 0.0766 \\
\hline $\mathrm{Q}(12)\{$ residuals $\}$ & 0.1318 & 0.1228 \\
\hline $\mathrm{Q}(24)\{$ residuals $\}$ & 0.0583 & 0.0569 \\
\hline $\mathrm{Q}(36)\{$ residuals $\}$ & 0.2682 & 0.2640 \\
\hline $\mathrm{Q}(6)\left\{\right.$ residuals $\left.^{2}\right\}$ & 0.6276 & 0.6260 \\
\hline $\mathrm{Q}(12)\left\{\right.$ residuals $\left.^{2}\right\}$ & 0.2211 & 0.2916 \\
\hline $\mathrm{Q}(24)\left\{\right.$ residuals $\left.^{2}\right\}$ & 0.3259 & 0.4953 \\
\hline $\mathrm{Q}(36)\left\{\right.$ residuals $\left.^{2}\right\}$ & 0.5809 & 0.7038 \\
\hline
\end{tabular}

The fitted n-SWARCH-L(3,2) model is presented in the following:

$$
\begin{aligned}
y_{t} & =\underset{(0.000723)}{0.002836}+u_{t} \\
u_{t} & =\sqrt{g_{S_{t}}} \widetilde{u}_{t} \text { where } S_{t}=1,2,3 \\
\widetilde{u}_{t} & =\sqrt{h_{t}} v_{t}
\end{aligned}
$$

where $v_{t} \sim N(0,1)$ and $h_{t}$ is given by:

$$
h_{t}=\underset{\left(3.341 \times 10^{-5}\right)}{0.0001551}+\underset{(0.0344)}{4.3201} \times 10^{-3} \widetilde{u}_{t-1}^{2}+\underset{(0.0482)}{0.2048 \widetilde{u}_{t-2}^{2}}+\underset{(0.0841)}{0.3210} d_{t-1} \widetilde{u}_{t-1}^{2}
$$


P.L.Valls Pereira; L.K. Hotta; L.A.R. de Souza \& N.M.C.G. de Almeida where

$$
\begin{aligned}
& d_{t-1}= \begin{cases}1 & \text { if } u_{t-1} \leq 0 \\
0 & \text { if } u_{t-1}>0,\end{cases} \\
& g_{1}=1, \quad g_{2}=\underset{(0.45452)}{1.82055,} \quad g_{3}=\underset{(1.42258)}{5.89178},
\end{aligned}
$$

and the transition matrix is given by:

$$
P=\left[\begin{array}{lll}
0.985644 & 0.000000 & 0.003107 \\
0.014356 & 0.974657 & 0.015038 \\
0.000000 & 0.025343 & 0.981855
\end{array}\right]
$$

\subsubsection{Cbond return series}

For the Cbond return series the Schawrz and Akaike criteria selected the t-SWARCH( 2,1$)$ and t-SWARCH-L(3,2) models, respectively (see table 3.14). The selected models have only a constant in the mean because the inclusion of an autoregressive structure did not improve the Akaike and Schwarz criteria. None of the proposed models was able to model completely the variance because the Qstatistics were significant at $5 \%$ level when applied to the square of the residuals of both selected models. This problem remained for more complex SWARCH models and was also detected in the 12Th. lag of the square of residuals of t-GARCH model with $1 \%$ of significance.

The estimate of the of t-SWARCH- $(2,1)$ model, which was selected by the Schwarz criterion is given in the following, with the estimated standard error of the estimates in parentheses:

$$
\begin{aligned}
y_{t} & =\underset{(0.0003669)}{0.001532}+u_{t} \\
u_{t} & =\sqrt{g_{S_{t}}} \widetilde{u}_{t} \text { where } S_{t}=1,2 \\
u_{t} & =\sqrt{h_{t}} v_{t}
\end{aligned}
$$

Revista de Econometria 19 (1) Maio 1999 
where $v_{t} \sim t(4.8656)$ and $h_{t}$ is given by:

$h_{t}=\underset{\left(1.3496 \times 10^{-5}\right)}{1.1656} \times 10^{-4}+\underset{(0.0681)}{0.1734 \widetilde{u}_{t-1}^{2}}$ where $g_{1}=1, g_{2}=\underset{(5.89456)}{0.94199}$

and the transition matrix is given by:

$$
P=\left[\begin{array}{ll}
0.992438 & 0.016661 \\
0.007562 & 0.983339
\end{array}\right]
$$

The average time in regimes 1 and 2 are approximately equal to 132 and 60 days, respectively. The scale factor that multiply the variance in the second regime is 5.894 , implying that the volatility in one regime is about 2.5 times higher than in the other.

Table 3.14

Goodness of Fit Statistics (Cbond)

\begin{tabular}{|c|c|c|}
\hline & t-SWARCH $(2,1)$ & t-SWARCH-L $(3,2)$ \\
\hline$A R$ order & 0 & 0 \\
\hline Degree of freedom & 4.8656303 & 5.6388254 \\
\hline Log-Lik & 2993.5720 & 3005.2523 \\
\hline AIC & -5.6191383 & -5.6317070 \\
\hline BIC & -5.5864178 & -5.5756146 \\
\hline $\mathrm{Q}(6)\{$ residuals $\}$ & 0.4322 & 0.2388 \\
\hline $\mathrm{Q}(12)\{$ residuals $\}$ & 0.0538 & $0.0287^{*}$ \\
\hline $\mathrm{Q}(24)\{$ residuals $\}$ & 0.1570 & 0.1065 \\
\hline $\mathrm{Q}(36)\{$ residuals $\}$ & 0.2557 & 0.2183 \\
\hline $\mathrm{Q}(6)\left\{\right.$ residuals $\left.^{2}\right\}$ & $0.0122^{*}$ & $0.0400^{*}$ \\
\hline $\mathrm{Q}(12)\left\{\right.$ residuals $\left.^{2}\right\}$ & $0.0004^{* *}$ & $0.0008^{* *}$ \\
\hline $\mathrm{Q}(24)\left\{\right.$ residuals $\left.^{2}\right\}$ & $0.0216^{*}$ & $0.0354^{*}$ \\
\hline $\mathrm{Q}(36)\left\{\right.$ residuals $\left.^{2}\right\}$ & 0.1614 & 0.1964 \\
\hline
\end{tabular}


The estimate for the t-SWARCH-L $(3,2)$ model is:

$$
\begin{aligned}
y_{t} & =\underset{(0.000359)}{0.001413} \\
u_{t} & =\sqrt{g S_{t}} \widetilde{u}_{t} \text { where } S_{t}=1,2,3 \\
\widetilde{u}_{t} & =\sqrt{h_{t}} v_{t}
\end{aligned}
$$

where $v_{t} \sim t(5,6389)$ and $h_{t}$ is given by:

$$
h_{t}=\underset{\left(1.1488 \times 10^{-5}\right)}{8.4535} \times 10^{-4}+\underset{(0.0461)}{0.0200 \widetilde{u}_{t-1}^{2}}+\underset{(0.0445)}{0.0813 \widetilde{u}_{t-2}^{2}}+\underset{(0.0933)}{0.1962 d_{t-1}} \widetilde{u}_{t-1}^{2}
$$

where

$$
g_{1}=1, \quad g_{2}=\underset{(0.3932)}{2.13032,} \quad g_{3}=\underset{(1.8270)}{7.86738}
$$

and the transition matrix is given by:

$$
P=\left[\begin{array}{lll}
0.993958 & 0.000000 & 0.008185 \\
0.006042 & 0.987229 & 0.007760 \\
0.000000 & 0.012771 & 0.984055
\end{array}\right]
$$

\subsubsection{Real/US Dollar exchange rate return series}

We worked with the exchange rate series multiplied by 100 in order to avoid numerical problems during the estimation process as we did before when a XARCH model was fitted. The best models selected by the Schwarz and Akaike criteria were the $\operatorname{SWARCH}(2,2)$ and SWARCH $(3,2)$ models, respectively, both with Student's t distribution (see table 3.15). These selected models, like the others, were not able to capture all the features of the series; the Q-statistics were significant both for the mean and the variance, i.e. for the residuals and for the square of the residuals. The leverage effect is not statistically significative for this series. 
Alternative Models to Extract Asset Volatility

Table 3.15

Goodness of Fit Statistics (Exchange Rate)

\begin{tabular}{lcc}
\hline & t-SWARCH(2,2) & t-SWARCH $(3,2)$ \\
\hline AR order & 0 & 0 \\
Degree of freedom & 2.9571174 & 3.3789389 \\
Log-Lik & 884.67895 & 888.86354 \\
AIC & -1.7657179 & -1.7681038 \\
BIC & -1.7262357 & -1.7138158 \\
Q(6)\{residuals\} & $0.0324^{*}$ & $0.0323^{*}$ \\
Q(12)\{residuals & $0.0115^{*}$ & $0.0079^{* *}$ \\
Q(24)\{residuals\} & $0.0013^{* *}$ & $0.0053^{* *}$ \\
Q(36)\{residuals\} & $0.0104^{*}$ & $0.0192^{*}$ \\
Q(6) residuals $^{2}$ \} & 0.9562 & 0.6679 \\
Q(12) residuals $^{2}$ \} & 0.9993 & 0.3443 \\
Q(24) residuals $^{2}$ \} & $0.0000^{* *}$ & 0.3874 \\
Q(36) residuals $^{2}$ \} & $0.0000^{* *}$ & 0.4100 \\
\hline
\end{tabular}

The estimated t-SWARCH $(2,2)^{5}$ model, selected by the Schwarz criterion is:

$$
\begin{aligned}
& y_{t}=0.023952+u_{t} \\
& u_{t}=\sqrt{g_{S_{t}}} \widetilde{u}_{t} \text { where } S_{t}=0,1 \\
& \widetilde{u}_{t}=\sqrt{h_{t}} v_{t}
\end{aligned}
$$

where $v_{t} \sim t(2,9571)$ and $h_{t}$ is given by:

$$
h_{t}=0.00264+0.3695 \widetilde{u}_{t-1}^{2}+0.3044 \widetilde{u}_{t-2}^{2}
$$

where $g_{1}=1, g_{2}=135.2056$ and the transition matrix is given by:

$$
P=\left[\begin{array}{ll}
0.999124 & 0.001493 \\
0.000876 & 0.998506
\end{array}\right]
$$

${ }^{5}$ Due to numerical problems the estimated standard deviations of the estimates are not reported. Inference in this case can be misleading. 
The estimated persistence in both regimes are very large and the scale factor is also large, about $11.6 \sqrt{135.20}$ ). Notice also that the values of $p_{11}$ and $p_{22}$ are near to 1.0 indicating that once in one regime the probability to changing to another regime is almost equal to zero. These facts are expected because we have a clear distinction of change of regime in the series.

Although t-SWARCH $(3,2)$ model does not completely specify the model it will be used in section 4.3 when we compare the volatility estimated by different models.

\subsection{Volatility estimated by different methods}

We first present the graphs of the estimated yearly volatility by the models selected in each class. We also present in the same graph the volatility estimated by the sample standard deviation using a 20 day moving average window.

In the Telebrás series we observed that the estimates given by the XARCH and the SV models follow the movements of the moving standard deviation estimates. On the other hand the SWARCH class model gave comparatively very large estimates for the peaks of the volatility and presented a more erratic behaviour. This could be explained by the larger persistence found by the SWARCH class model in both regimes.

The Cbond series presents the same features found in the Telebrás series, i.e. the volatility estimated by the XARCH and SV models follow the volatility estimated by the moving standard deviation, which did not occur with the volatility estimated by the SWARCH model. In general the conditional volatility tends to revert quickly to the non conditional volatility level because the estimated coefficient of the ARCH structure is small. 


\section{Annual Telebras Volatility}

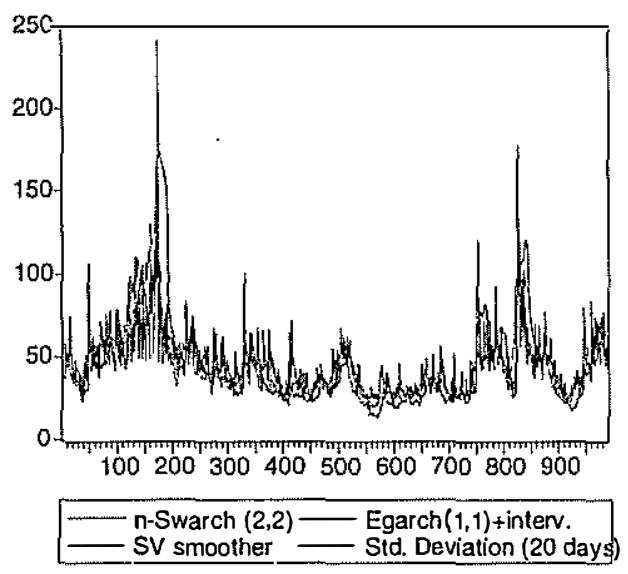

Figure 3.4

Annual Cbond Volatilities

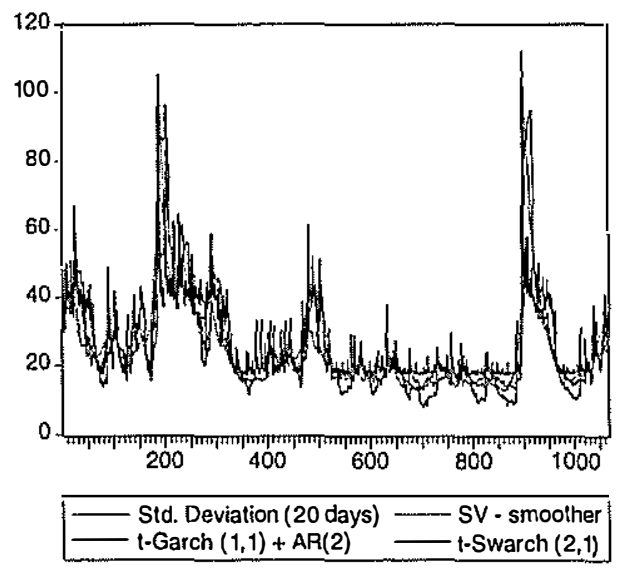

Figure 3.5

The estimates of the volatility of the exchange rate series follow the movements of the moving standard deviation estimates only after the 250-Th. observation, and the increase in volatility is larger for the XARCH and SWARCH classes models. However, before the 
250-Th. observation the volatility estimated by the XARCH model is very erratic and completely different than the moving standard deviation estimates.

\section{Annual ReaVUS Dollar Exchange Rate Volatility}

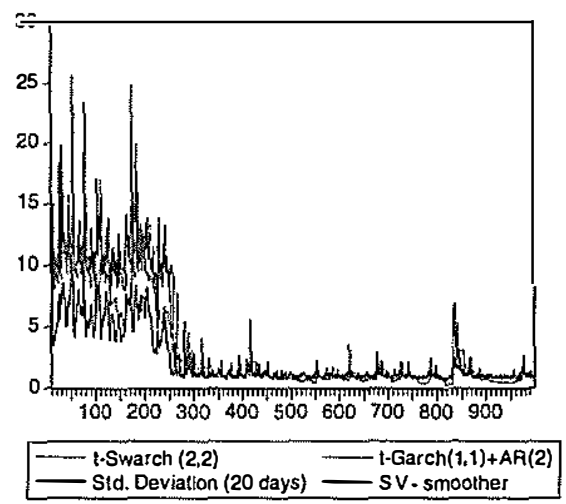

Figure 3.6

\section{Comparison of the Estimated Volatility}

In this section we compare the estimates of the volatility by the models presented previously using different prediction criteria and loss functions.

Two prediction were considered in the analysis. The first is the traditional one-step-ahead prediction in-the-sample where the models were estimated using all the available data set. In the second case we evaluated the one-step ahead out-the-sample prediction (i.e. using only the available observations) for the last 100 observations. First we selected and estimated the model leaving out the last 100 observations and evaluated the one-step ahead prediction. In order to perform the next one-step-ahead prediction we should include one more observation and select and estimate the model. However this would be cumbersome and considering that we do not expect a 
large difference with the previous model we kept the same estimated parameters model to estimate 20 one-step-ahead predictions. For the 21-st. prediction we included the last 20 observations, dropped the first 20 observations and re-estimated the model. This model was used to evaluate 20 new on-step-ahead predictions. We repeated this procedure until we evaluate all the 100 one-step-ahead predictions. We choose 20 observations because we are using daily data and 20 correspond to approximately one month or half of the maturity of an option. This procedure allow us to use the same sample size and follow the possible modifications in the series and compare the outof-sample performance of the models selected by the in-the-sample performance.

The performance of the models in-the-sample was evaluated through the five loss functions given in the following:

$$
\begin{aligned}
M S E & \left.=\frac{1}{T} \sum_{t=1}^{T} \widehat{u}_{t}^{2}-\widehat{\sigma}_{t \mid t-1}^{2}\right)^{2} \\
M A E & =\frac{1}{T} \sum_{t=1}^{T}\left|\widehat{u}_{t}^{2}-\widehat{\sigma}_{t \mid t-1}^{2}\right| \\
L E^{2} & =\frac{1}{T} \sum_{t=1}^{T}\left[\ln \left(\widehat{u}_{t}^{2}\right)-\ln \left(\widehat{\sigma}_{t \mid t-1}^{2}\right)\right]^{2} \\
|L E| & =\frac{1}{T} \sum_{t=1}^{T}\left|\ln \left(\widehat{u}_{t}^{2}\right)-\ln \left(\widehat{\sigma}_{t \mid t-1}^{2}\right)\right|
\end{aligned}
$$

$L R=\frac{\left.£_{1} \widehat{\theta}^{*}\right)}{\left.£_{0} \widehat{\theta}^{*}\right)}$, where $£_{1}$ is the log-likelihood of the model with modelling of the variance and $£_{0}$ is the log-likelihood of the model when the variance is taken as constant. Both values are maximum likelihood values. 
These values was evaluated only for the first type of prediction of the volatility, i.e. for the in-the-sample prediction. We also evaluated the relative frequency of cases where the returns are outside the confidence interval. The confidence intervals were evaluated using the conditional variance estimated by both procedure, in and outside the sample.

\subsection{Telebrás return series}

Among the XARCH class models the models with more complex specification of the volatility dynamic - $\operatorname{GARCH}(3,2)-$ had better out-the-sample performance according to the criterion of returns outside the prediction interval (see table 4.1), while the more parsimonious model - $\operatorname{GARCH}(1,1)$ presented better in-the-sample performance. Although the EGARCH presented the worst performance, according to this criterion, it is not to possible to reject the null hypothesis of proportions outside the confidence interval equal to $5 \%$ in any case. However we must take into account that the power of the test is small when we consider out-the-sample prediction. Considering the loss function defined earlier (table 4.2) the EGARCH presented the best performance according to MSE and MAE criteria, and presented the best improvement of the likelihood in relationship to the likelihood without modelling the variance (criterion LR). The t-GARCH(3,2) was the best according to $L E^{2}$ and $|L E|$ criteria.

The MSE and MAE decreased considerably when intervention is included in the XARCH models increasing the adherence of the estimated conditional variance to the "instantaneous volatility". The problem with the frequency of observations outside the confidence interval also disappeared in the EGARCH both inside and outside the sample. After the inclusion of the intervention in every models the EGARCH still presents the smallest MSE and MAE among the 
three models, the best decrease in the likelihood (LR criterion) and is the best according to both AIC and BIC criteria. These results indicates that the EGARCH with interventions is the best model for the Telebrás series for the period considered.

Table 4.1

Proportion of Forecasts Outside the Confidence Interval (Telebrás)

\begin{tabular}{lccc}
\hline & $\begin{array}{c}\text { Prediction exercise } \text { I }^{1} \\
\text { in-t he-sample }\end{array}$ & $\begin{array}{c}\text { Prediction exercise II } \\
\text { in-t he-sample }\end{array}$ \\
\hline out-t he-sample \\
n-GARCH(1,1) & $4.97 \%$ & $5.19 \%$ & $3 \%$ \\
n-GARCH(3,2) & $5.07 \%$ & $5.30 \%$ & $4 \%$ \\
t-GARCH(1,1) & $4.87 \%$ & $5.08 \%$ & $3 \%$ \\
t-GARCH(3,2) & $5.17 \%$ & $5.30 \%$ & $4 \%$ \\
EGARCH(1,1)-AR(0) & $4.16 \%$ & $4.18 \%$ & $2 \%$ \\
EGARCH(1,1)-AR(1) & $4.36 \%$ & $4.29 \%$ & $2 \%$ \\
n-GARCH(1,1)-dummy & $5.27 \%$ & $5.42 \%$ & $3 \%$ \\
t-GARCH(1,1)-dummy & $4.97 \%$ & $5.19 \%$ & $3 \%$ \\
EGARCH(1,1)-dummy & $4.97 \%$ & $4.85 \%$ & $3 \%$ \\
n-SWARCH-L(2,2) & $5.37 \%$ & $5.19 \%$ & $4 \%$ \\
n-SWARCH-L(3,2) & $5.17 \%$ & $5.30 \%$ & $3 \%$ \\
SV-Model I & $4.87 \%$ & $4.98 \%$ & $4 \%$ \\
SV-Model II & $4.98 \%$ & $5.42 \%$ & $4 \%$ \\
SV-Model II I & $4.98 \%$ & $4.97 \%$ & $5 \%$ \\
\hline
\end{tabular}

Notes:

(1) Use all the sample for identification, selection and estimation of the models.

(2) Leave out the last 100 observations only for prediction. Selection and estimation of the models are done without this 100 observations.

Comparing the prediction of the prediction of the two fitted SWARCH, models (see table 4.1) the performance of the SWARCH$\mathrm{L}(3,2)$ model was better than the performance of the SWARCH$\mathrm{L}(2,2)$ model for the in-the-sample prediction, but the performance of the second model was better in the second prediction exercise. The SWARCH-L $(3,2)$ model also presented better performance than the SWARCH-L $(2,2)$. model, according to statistics MAE, $\mathrm{LE}^{2},|L E|$ and LR (see table 4.2), but the second presented smaller MSE. 
For the SV class, models II and II presented the best results for the in-the-sample prediction exercise (see table 4.1), while for the second prediction exercise (see table 4.1) Model I produced the best results in the sample, followed by Model III with Model II producing the worst result. However, for the out-of-sample results Model III was the best followed by Models II and I.

Table 4.2

Forecast Accurace Using Differents Loss Functions (Telebrás)

\begin{tabular}{lccccc}
\hline & $M S E$ & $M A E$ & $L E^{2}$ & $|L E|$ & $L R$ \\
\hline n-GARCH(1,1) & $1.650 \times 10^{-5}$ & $1.125 \times 10^{-3}$ & 6.2438 & 1.7665 & 1.0929 \\
n-GARCH(3,2) & $1.578 \times 10^{-5}$ & $1.119 \times 10^{-3}$ & 6.3564 & 1.7644 & 1.0948 \\
t-GARCH(1,1) & $1.565 \times 10^{-5}$ & $1.131 \times 10^{-3}$ & 6.2273 & 1.7629 & 1.0993 \\
t-GARCH(3,2) & $1.580 \times 10^{-5}$ & $1.124 \times 10^{-3}$ & 6.1921 & 1.7553 & 1.1008 \\
EGARCH(1,1)-AR(0) & $1.415 \times 10^{-5}$ & $1.015 \times 10^{-3}$ & 6.7497 & 1.7696 & 1.1012 \\
EGARCH(1,1)-AR(1) & $1.489 \times 10^{-5}$ & $1.007 \times 10^{-3}$ & 6.4554 & 1.7616 & 1.1017 \\
n-GARCH(1,1)-dummy & $2.652 \times 10^{-6}$ & $9.183 \times 10^{-4}$ & 6.1952 & 1.7554 & 1.1021 \\
t-GARCH(1,1)-dummy & $2.623 \times 10^{-6}$ & $9.196 \times 10^{-4}$ & 6.3105 & 1.7528 & 1.1058 \\
EGARCH(1,1)-dummy & $2.497 \times 10^{-6}$ & $8.815 \times 10^{-4}$ & 6.4579 & 1.7541 & 1.1074 \\
n-SWARCH-L(2,2) & $1.447 \times 10^{-5}$ & $1.050 \times 10^{-3}$ & 6.2336 & 1.7677 & 1.0996 \\
n-SWARCH-L(3,2) & $1.447 \times 10^{-5}$ & $1.048 \times 10^{-3}$ & 6.2047 & 1.7638 & 1.1005 \\
SV-Model I & $1.447 \times 10^{-5}$ & $9.507 \times 10^{-4}$ & 3.8815 & 1.4292 & $-(2)$ \\
SV-Model II & $1.448 \times 10^{-5}$ & $9.527 \times 10^{-4}$ & 3.8804 & 1.4324 & - \\
SV-Model III & $3.447 \times 10^{-5}$ & $1.038 \times 10^{-3}$ & 3.8567 & 1.4243 & - \\
\hline
\end{tabular}

Notes:

(1) Only for prediction exercise inside the sample and for models estimated using all the available information. The criteria was evaluated as explained in the beginning of the section.

(2) Not comparable since the denominator evaluate the Log-likelihood for the returns and the numerator after the transformation (2.15).

Model I was also the best according to MSE and MAE criteria (see table 4.2), and Model III according to $L E^{2}$ and $|L E|$ criteria.

Revista de Econometria 19 (1) Maio 1999 


\subsection{Cbond return series}

For the XARCH models the t-GARCH model was clearly the best in terms of frequency of returns outside the confidence interval, both in and out the sample (see table 4.3). In terms of loss function (see table 4.4), the EGARCH model presented again the smallest MSE and MAE. This is explained by the fact that this model can react quicker to increases and decreases of the conditional volatility in the presence of shocks and follow the "instantaneous volatility". The t-GARCH presented the best performance according to $L E^{2}$, $|L E|$ and change of likelihood (LR) criteria.

Table 4.3

Proportion of Forecasts Outside the Confidence Interval (Cbond)

\begin{tabular}{lccc}
\hline & $\begin{array}{c}\text { Prediction exercise I } \\
\text { in-the-sample }\end{array}$ & $\begin{array}{c}\text { Prediction exercise II } \\
\text { in-the-sample out-the-sample }\end{array}$ \\
\hline n-GARCH(1,1)-AR(0) & $5.36 \%$ & $5.39 \%$ & $3 \%$ \\
n-GARCH(1,1)-AR(2) & $5.26 \%$ & $5.50 \%$ & $3 \%$ \\
t-GARCH(1,1)-AR(0) & $5.17 \%$ & $5.29 \%$ & $3 \%$ \\
t-GARCH(1,1)-AR(2) & $5.17 \%$ & $5.19 \%$ & $4 \%$ \\
EGARCH(1,1)-AR(0) & $5.64 \%$ & $5.19 \%$ & $3 \%$ \\
EGARCH(1,1)-AR(1) & $5.64 \%$ & $5.29 \%$ & $3 \%$ \\
t-SWARCH(2,1) & $4.88 \%$ & $4.86 \%$ & $5 \%$ \\
t-SWARCH-L(3,2) & $4.79 \%$ & $4.86 \%$ & $4 \%$ \\
SV-Model I & $5.64 \%$ & $5.61 \%$ & $5 \%$ \\
SV-Model II & $5.74 \%$ & $5.61 \%$ & $5 \%$ \\
\hline
\end{tabular}

For the SWARCH models the more parsimonious model with Student-t disturbances, i.e. t-SWARCH $(2,1)$ had the best overall performance in terms of prediction both in and out of sample (see table 4.3). On the other hand, as reported in table 4.4, we have that model t-SWARCH-L $(3,2)$ was the best one according to all loss function. 
For the SV models the best model in terms of frequency of prediction in the first prediction exercise is model I, while in second prediction exercise both models gave similar results in and out of sample (table 4.3). Model II gave the best results according to all loss function criteria, except for the MSE criterion (table 4.4).

Table 4.4

Forecast Accurace Using Differents Loss Functions (Cbond)

\begin{tabular}{lccccc}
\hline & $M S E$ & $M A E$ & $L E^{2}$ & $|L E|$ & $L R$ \\
\hline n-GARCH(1,1)-AR(0) & $1.965 \times 10^{-6}$ & $4.269 \times 10^{-4}$ & 7.8215 & 2.0507 & 1.0881 \\
n-GARCH(1,1)-AR(2) & $1.952 \times 10^{-6}$ & $4.259 \times 10^{-4}$ & 8.7161 & 2.0975 & 1.0882 \\
t-GARCH(1,1)-AR(0) & $1.969 \times 10^{-6}$ & $4.195 \times 10^{-4}$ & 7.8057 & 2.0455 & 1.1127 \\
t-GARCH(1,1)-AR(2) & $1.967 \times 10^{-6}$ & $4.202 \times 10^{-4}$ & 7.7259 & 2.0455 & 1.1128 \\
EGARCH(1,1)-AR(0) & $1.777 \times 10^{-6}$ & $3.838 \times 10^{-4}$ & 8.8763 & 2.0969 & 1.0954 \\
EGARCH(1,1)-AR(1) & $1.761 \times 10^{-6}$ & $3.830 \times 10^{-4}$ & 9.0177 & 2.1091 & 1.0955 \\
t-SWARCH(2,1) & $1.940 \times 10^{-6}$ & $4.155 \times 10^{-4}$ & 8.1209 & 2.1144 & 1.1075 \\
t-SWARCH-L(3,2) & $1.906 \times 10^{-6}$ & $3.976 \times 10^{-4}$ & 7.8588 & 2.0650 & 1.1118 \\
SV-Model I & $2.005 \times 10^{-6}$ & $3.540 \times 10^{-4}$ & 7.0620 & 1.8652 & - \\
SV-Model II & $2.005 \times 10^{-6}$ & $3.534 \times 10^{-4}$ & 7.0540 & 1.8640 & - \\
\hline
\end{tabular}

\subsection{Real/US dollar exchange rate series}

In the XARCH family the best model according to the frequency of returns inside the confidence interval was the $\operatorname{GARCH}(2,1)$ for the in-the-sample prediction and the $\operatorname{GARCH}(3,1)$ for the out-of-sample prediction. Thus, if the goal is to construct confidence intervals for the returns this result could indicate that models with more complex conditional variance structure have better performance. Besides, models with normal disturbances presents frequency of observations outside the in-the-sample confidence interval near $6 \%$ (for 
nominal frequency of 5\%) and models with Student's t disturbances near $4 \%$. This is explained by the large dispersion found in the first 250 observations which are responsible by the sub-estimation of the conditional variance in this part of the series when we used normal distribution for the disturbances and the super-estimation in the second part of the series when we used Student's t distribution. The frequency of rejection is shown in table 4.5 .

\section{Table 4.5}

Proportion of Forecasts Outside the Confidence Interval (Exchange Rate)

\begin{tabular}{lccc}
\hline & $\begin{array}{c}\text { Prediction exercise I } \\
\text { in-the-sample }\end{array}$ & $\begin{array}{c}\text { Prediction exercise II } \\
\text { in-the-sample out-the-sample }\end{array}$ \\
\hline n-GARCH(3,1)-AR(2) & $6.34 \%$ & $6.26 \%$ & $5 \%$ \\
n-GARCH(2,1)-AR(2) & $6.04 \%$ & $5.93 \%$ & $4 \%$ \\
t-GARCH(1,1)-AR(0) & $4.02 \%$ & $3.58 \%$ & $4 \%$ \\
t-GARCH(1,1)-AR(2) & $4.12 \%$ & $3.69 \%$ & $3 \%$ \\
t-SWARCH(2,2) & $3.62 \%$ & $4.03 \%$ & $3 \%$ \\
t-SWARCH(3,2) & $4.22 \%$ & $4.47 \%$ & $3 \%$ \\
SV-Model I & $7.01 \%$ & $8.63 \%$ & $5 \%$ \\
SV-Model II & $8.05 \%$ & $9.17 \%$ & $4 \%$ \\
\hline
\end{tabular}

No model is clearly superior to others according to the defined loss functions: n-GARCH(2,1) is the best model according to MSE and $L E^{2}$ criteria, n-GARCH(3,1) is the best one according to MAE and $|L E|$ criteria and t-GARCH(1,1)-AR(2) presented the best improvement in the likelihood in relationship to the model with constant variance. This results seem to support the previous conclusion based on the predictions outside the confidence interval that models with more flexible dynamic structure in the conditional variance have better performance.

For the SWARCH models the prediction results reported in table 4.5 , indicate clearly that t-SWARCH$(3,2)$ has the best perfor- 
mance according to in-the-sample prediction and to all defined loss functions (see table 4.6).

For the SV models, the prediction results reported in table 4.5, the best model is always Model I which is the SV model with local level. This model is also the best according to MSE and MAE criteria (see table 4.6), but Model II is the best according to the other two criteria.

Table 4.6

Forecast Accurace Using Differents Loss Functions (Exchange Rate)

\begin{tabular}{lccccc}
\hline & $M S E$ & $M A E$ & $L E^{2}$ & $|L E|$ & $L R$ \\
\hline t-GARCH(3,1)-AR(2) & 0.1513 & 0.1086 & 8.6397 & 2.1341 & -4.1725 \\
n-GARCH(2,1)-AR(2) & 0.1493 & 0.1118 & 8.6332 & 2.1415 & -4.1309 \\
t-GARCH(1,1)-AR(0) & 0.1542 & 0.1377 & 9.2636 & 2.3079 & -4.4920 \\
t-GARCH(1,1)-AR(2) & 0.1822 & 0.1431 & 10.2163 & 2.3565 & -4.5082 \\
t-SWARCH(2,2) & 0.4417 & 0.1603 & 9.1411 & 2.3815 & -4.433 \\
t-SWARCH(3,2) & 0.2916 & 0.1376 & 8.8657 & 2.3188 & -4.454 \\
SV-Model I & $4.2389 \times 10^{-2}$ & $4.3889 \times 10^{-2}$ & 3.0949 & 1.2804 & - \\
SV-Model II & $4.1636 \times 10^{-2}$ & $4.3699 \times 10^{-2}$ & 3.2084 & 1.3079 & - \\
\hline
\end{tabular}

Obs: The results presented in table are for returns multiplied by 100 . In order to have the MSE and MAE of the original series the results must be multiplied by $10^{-8}$ and $10^{-4}$, respectively. $L^{2}$ and $[L E \mid$ are invariant under transformation. For the $L R$ there is no direct transformation to recuperate the value for the original series. The ordination of the models, however, is invariant under transformation.

According to the results of tables 4.7, 4.9 and 4.11 we have that models of the SV class have the best performance, followed by models of XARCH class and lastly models of SWARCH class. The results of tables 4.8, 4.10 and 4.12 also indicates the models of SV class as the best, but in second we have models of SWARCH class and lastly models of XARCH class. 
Alternative Models to Extract Asset Volatility

Table 4.7

Best Class of Models - Telebrás

Class\Criterion PI PII-in PII-out MSE MAE LE ${ }^{2}|\mathrm{LE}|$ LR General

\begin{tabular}{llllllllll}
\hline GARCH & $2^{o}$ & $3^{o}$ & $3^{o}$ & $3^{o}$ & $2^{o}$ & $3^{o}$ & $2^{o}$ & $2^{o}$ & $3^{o}$ \\
SV & $1^{o}$ & $1^{o}$ & $1^{o}$ & $2^{o}$ & $1^{o}$ & $1^{o}$ & $1^{o}$ & $\overline{ }$ & $1^{o}$ \\
SWARCH & $3^{o}$ & $2^{o}$ & $2^{o}$ & $1^{o}$ & $3^{o}$ & $2^{o}$ & $3^{o}$ & $1^{o}$ & $2^{o}$ \\
\hline
\end{tabular}

Table 4.8

Best Model - Telebrás

Model \Criterion

PI PII-in PII-out MSE MAE LE ${ }^{2}|L E|$ LR

n-GARCH $(1,1)$

$\mathrm{n}-\mathrm{GARCH}(3,2)$

$\operatorname{GARCH}(1,1)-\mathrm{t}$

$3^{o}$

$\operatorname{GARCH}(3,2)-t$

$\operatorname{EGARCH}(1,1)+\mathrm{AR}(0)$

$\operatorname{EGARCH}(1,1)+\operatorname{AR}(1)$

n-GARCH(1,1)-d ummy

GARCH(1,1)-t-dummy

$\operatorname{EGARCH}(1,1)+$ dummy $3^{o}$

$\begin{array}{lll}3^{\circ} & 2^{\circ} & 3^{o} \\ 2^{o} & 3^{o} & 2^{o} \\ 1^{o} & 1^{o} & 1^{o}\end{array}$

n-SWARCH-L $(2,2)$

n-SWARCH-L $(3,2)$

SV-Model I

SV-Model II

SV-Model III

$\begin{array}{lllllll}2^{o} & 1^{o} & 3^{o} & & 3^{o} & 2^{o} \\ 1^{o} & 2^{o} & 1^{o} & 2^{o} & & 2^{o} & 3^{o} \\ \end{array}$

Table 4.9

Best Class of Models - Cbond

\begin{tabular}{lccccccccc}
\hline Class \Criterion & PI & PII-in & PII-out & MSE & MAE & LE $^{2}$ & $|\mathrm{LE}|$ & LR & General \\
\hline GARCH & $2^{o}$ & $1^{o}$ & $2^{o}$ & $2^{o}$ & $3^{o}$ & $2^{o}$ & $2^{o}$ & $2^{o}$ & $1^{o}$ \\
SV & $3^{o}$ & $3^{o}$ & $1^{o}$ & $3^{o}$ & $1^{o}$ & $1^{o}$ & $1^{o}$ & - & $1^{o}$ \\
SWARCH & $1^{o}$ & $2^{o}$ & $3^{o}$ & $1^{o}$ & $2^{o}$ & $3^{o}$ & $3^{o}$ & $1^{o}$ & $2^{o}$
\end{tabular}


P.L.Valls Pereira; L.K. Hotta; L.A.R. de Souza \& N.M.C.G. de Almeida

Table 4.10

Best Model - Cbond

\begin{tabular}{|c|c|c|c|c|c|c|c|c|}
\hline Model \Criterion & PI & PII-in & PII-out & MSE & MAE & $\mathrm{LE}^{2}$ & $|\mathrm{LE}|$ & LR \\
\hline \multicolumn{9}{|l|}{ n-GARCH(1,1)-AR(0) } \\
\hline \multicolumn{9}{|l|}{ n-GARCH(1,1)-AR(2) } \\
\hline t-GARCH$(1,1)-A R(0)$ & $3^{o}$ & & & & & & & $2^{o}$ \\
\hline t-GARCH( $(1,1)-\operatorname{AR}(2)$ & $2^{o}$ & $3^{o}$ & & & & $3^{o}$ & $3^{o}$ & $1^{o}$ \\
\hline $\operatorname{EGARCH}(1,1)+\operatorname{AR}(0)$ & & $2^{o}$ & & $2^{o}$ & & & & \\
\hline $\operatorname{EGARCH}(1,1)+\operatorname{AR}(1)$ & & & & $1^{o}$ & $3^{o}$ & & & \\
\hline SWARCH-(2,1)-t & $1^{o}$ & $1^{o}$ & $1^{o}$ & & & & & \\
\hline SWARCH-L(3,2)-t & & & & $3^{o}$ & & & & $3^{o}$ \\
\hline SV-Model I & & & $1^{o}$ & & $2^{o}$ & $2^{o}$ & $2^{o}$ & \\
\hline SV-Model II & & & $1^{o}$ & & $1^{o}$ & $1^{o}$ & $1^{o}$ & \\
\hline
\end{tabular}

Table 4.11

Best Class of Models - Exchange Rate

\begin{tabular}{lccccccccc}
\hline Class $\backslash$ Criterion & PI & PII-in & PII-out & MSE & MAE & LE & $|\mathrm{LE}|$ & LR & General \\
\hline GARCH & $2^{o}$ & $2^{o}$ & $2^{o}$ & $2^{o}$ & $2^{o}$ & $2^{o}$ & $2^{o}$ & $1^{o}$ & $2^{o}$ \\
SV & $3^{o}$ & $3^{o}$ & $1^{o}$ & $1^{o}$ & $1^{o}$ & $1^{o}$ & $1^{o}$ & $\overrightarrow{ }$ & $1^{o}$ \\
SWARCH & $1^{o}$ & $1^{o}$ & - & $3^{o}$ & $3^{o}$ & $2^{o}$ & $3^{o}$ & $1^{o}$ & $3^{o}$ \\
\hline
\end{tabular}

Table 4.12

Best Model - Exchange Rate

\begin{tabular}{|c|c|c|c|c|c|c|c|c|c|}
\hline Model $\backslash$ Criterion & PI & PII-in & PII-out & MSE & MAE & $\mathrm{LE}^{2}$ & $|\mathrm{LE}|$ & LR & \\
\hline $\mathrm{n}-\mathrm{GARCH}(3,1)-\mathrm{AR}(2)$ & & & $1^{o}$ & & $3^{o}$ & & $3^{o}$ & & \\
\hline $\mathrm{n}-\mathrm{GARCH}(2,1)-\mathrm{AR}(2)$ & & $2^{o}$ & $3^{o}$ & $3^{o}$ & & $3^{\circ}$ & & & \\
\hline t-GARCH$(1,1)-\operatorname{AR}(0)$ & $3^{o}$ & & & & & & & & $2^{o}$ \\
\hline t-GARCH$(1,1)-A R(2)$ & $2^{o}$ & & & & & & & & $1^{o}$ \\
\hline t-SWARCH $(2,2)$ & & $3^{o}$ & & & & & & & \\
\hline t-SWARCH $(3,2)$ & $1^{o}$ & $1^{o}$ & & & & & & $3^{o}$ & \\
\hline $\begin{array}{l}\text { SV-Model I } \\
\text { SV-Model II }\end{array}$ & & & $1^{o}$ & $\begin{array}{l}2^{o} \\
1^{o}\end{array}$ & $\begin{array}{l}2^{o} \\
1^{o}\end{array}$ & $\begin{array}{l}1^{o} \\
2^{o}\end{array}$ & $\begin{array}{l}1^{o} \\
2^{o}\end{array}$ & & \\
\hline
\end{tabular}

Revista de Econometria 19 (1) Maio 1999 


\section{Conclusions}

This paper compared the estimates of volatility of three Brazilian series, Telebrás, Cbond and Real/US Dollar exchange, by different classes of models, using different criteria.

According to different loss function the SV model had the best performance, except for the MSE loss function for the Telebrás and Cbond series and LR criterion when models of SWARCH were superior. Using the criterion of prediction outside the in-the-sample confidence interval the SV was the best for the Telebrás series and the SWARCH was the best for the Cbond and exchange rate series. The SV model was the best for all three series considering the out-the-sample prediction.

In summary we could say that the SV model was the best, except for the MSE criterion. It also had the best performance if we take into account all the criteria, loss function and prediction outside the confidence interval. This result has important implications in the context of Value-at-Risk methodology and in option pricing, since we worked with confidence interval prediction using a prediction horizon compatible with the option maturity time.

Submitted on March 1999 and revised on May 1999.

\section{References}

Black, F. 1976. "Studies in stock price volatility changes". Proceedings of the 1976 Business Meeting of the Business and Economic Statistics Section, American Statistical Association, 177-181.

Bollerslev, T. 1986. "Generalized autoregressive conditional heteroskedasticity". Journal of Econometrics, 31:307-327.

. 1987. "A conditionally heteroskedastic time series model for speculative prices and rate of return". Review of Economics and Statistics, 69:542-547. 
Breidt, F.J. \& Carriquirt, E.L. 1996. "Improved quasi-maximum likelihood estimation for stochastic volatility models". In Zellner, A. \& Lee, J.S. (eds). Modelling and Prediction: Honouring Seymour Geisel. New York: Springer-Verlag.

Cai, J. 1994. "A Markov model of switching -regime ARCH". Journal of Business 6 Economic Statistics, 12:309-316.

Cao, C.Q. \& Tsay, R.S. 1993. "Nonlinear time-series analysis of stock volatilities". In Pesaran, M.H. \& Potter, M. (eds). Nonlinear Dynamics, Chaos and Econometrics, New York, John Wiley \& Sons.

Dueker, M.J. 1997. "Markov switching in GARCH processes and ean-reverting stock-market volatility". Journal of Business 8 Economic Statistics, 15:26-34.

Engle, R.F. 1982. "Autoregressive conditional heteroskedasticity with estimates of the variance of United Kingdom inflation". Econometrica, 50:987-1007.

\& Bollerslev, T. 1986. "Modelling the persistence of conditional variances (with discussion)". Econometrics Reviews, $\mathbf{5}(1): 81-87$.

\& Gonzalez-Rivera, G. 1991. "Semiparametric ARCH models". Journal of Business \& Economic Statistics, 9:345-359.

Foster, D.P. \& Nelson, D.B. 1996. "Continuous records asymptotics for rolling sample variance estimators". Econometrica, 64:139174.

Granger, C.W.J. \& Newbold, P. 1977. Forecasting Economic Time Series. New York: Academic Press.

Hamilton, J.D. \& Susmel, R. 1994. "Autoregressive conditional heteroskedasticity and changes in regime". Journal of Econometrics, 64:307-333. 
Harvey, A.C.; Ruiz E. \& Shephard, N. 1994. "Multivariate stochastic variance models". Review of Economics Studies, 61:247-264. Herencia, M.Z.; Hotta, L.K.; Valls Pereira, P.L.; Ferreira, J. \& Mecchi, M. 1995. "Volatilidade nos retornos de Telebrás: uma comparação entre abordagem ARCH and modelo de volatilidade estocástica". Anais do XVII Encontro Brasileiro de Econometria, 1:587-621.

; Hotta, L.K. \& Valls Pereira, P.L. 1998. "Filtragem e previsão em modelos de volatilidade: volatilidade estocástica versus GARCH". Revista Brasileira de Economia, 52(2):241-278.

Jacquier, E.; Polson, N.G. \& Rossi, P.E. 1994. "Bayesian analysis of stochastic volatility models (with discussion)". Journal of Business \& Economic Statistics, 12:371-417.

Kim, S.; Shephard, N. \& Chib, S. 1998. "Stochastic volatility: likelihood inference and comparison with ARCH model". Review of Economics Studies, 65:361-393.

Lee, J.H.H. 1991. "A Lagrange multiplier test for GARCH models". Economic Letters, 37:265-271.

Li, W.K. \& Mark, T.K. 1994. "On the squared residual autocorrelation in non-linear time series with conditional heteroskedasticity". Journal of Time Series Analysis, 15:627-636.

Mc Leod, A.I. \& Li, W.K. 1983. "Diagnostic checking ARMA time series models using squared residual autocorrelations". Journal of Time Series Analysis, 4:269-273.

Nelson, D.B. 1991. "Conditional heteroskedasticity in asset returns: a new approach". Journal of Business 8 Economic Statistics, 59:347-370.

\& Foster, D.P. 1994. "Asymptotic filtering theory for univariate ARCH models". Econometrica, 62:1-41. 
P.L.Valls Pereira; L.K. Hotta; L.A.R. de Souza \& N.M.C.G. de Almeida

Pagan, A. \& Schwert, G.W. 1990. "Alternative models for conditional stock volatility". Journal of Econometrics, 45:267-290

Taylor, S.J. 1980. "Conjectured models for trend in financial prices, tests and forecasts". Journal of The Royal Statistical Society, A-143:338-362.

Tong, H. 1990. Non-linear Time Series: a Dynamical System Approach. Oxford: Oxford University Press.

Weiss, A.A. 1986. "Asymptotic theory for ARCH models: estimation and testing". Econometric Theory, 2:107-131.

White, H. 1982. "Maximum likelihood estimation of misspecified models". Econometrica, 50:1-25. 
